\title{
The Legitimacy of Transnational Startups: The Case of Canadian-Iranian Startups
}

\author{
By \\ Seyed Ayat Tadjalli
}

A thesis submitted to the Faculty of Graduate Studies and Research in partial fulfillment of the requirement for the degree of the

Master of Applied Science

in

Technology Innovation Management

Carleton University

Ottawa, Ontario

(C) January 19, 2018, Seyed Ayat Tadjalli 


\begin{abstract}
Building legitimacy is one of the main challenges of every entrepreneur, especially transnational ones. The study has employed a combination of qualitative and quantitative methods including grounded theory and Borda count method to capture the perception of new transnational ventures (NTVs) from the sources of legitimacy for financiers and grant providers and the most important challenges of NTVs. The results from studying six CanadianIranian NTVs show that the most important challenges face NTVs to obtain legitimacy are "Insufficient understanding of Canadian business environment and business language", "Procuring funding", and "Building a network" Also, the most important perceived criteria of legitimacy are "the amount of investment in the business", "experience and background of the founder and director", and "credit history" of the owner(s). The contribution of the research is providing an examination of the intersection of NTVs and legitimacy. NTVs may use the results to manage their legitimacy.
\end{abstract}




\section{Acknowledgement}

To my sweethearts, Ayra and Parnia, and my love, Zahra

I would like to thank my thesis supervisor, Professor Tony Bailetti, for all his generous help and advice not only while I undertook this project, but also throughout my time at the TIM Program. He has always been an open sharer of knowledge, allowing this study to unfold as I envisioned, while gently steering me in the right direction at crucial points.

My gratitude also goes to the entrepreneurs who were involved in the interviews for this research project and kindly shared their experiences with me. Without their passionate participation and input, the case studies could not have been successfully conducted.

I would like to thank all of the faculty at TIM as well, both for their engaging courses as well as their feedback on this study. The support I have received from the TIM staff has also been invaluable, and I thank them greatly.

To my friends, I am grateful for your help with this project in the form of providing feedback, suggestions, proofreading assistance, and spiritual support.

Finally, I would like to thank my family. My daughters and my wife have given me continual spiritual support throughout this journey. They were patient and understanding when I spent time on the research that would have otherwise been devoted to them. 


\section{Table of Contents}

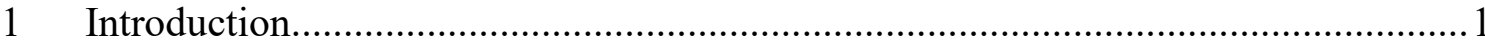

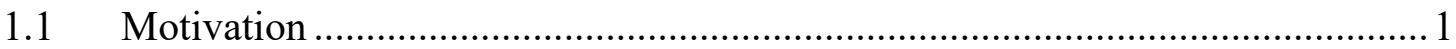

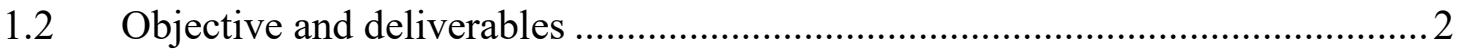

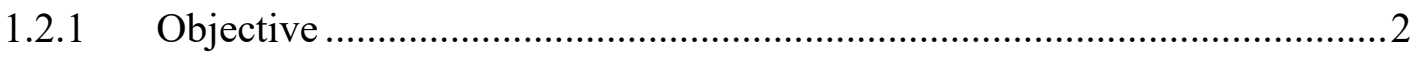

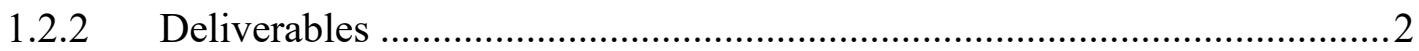

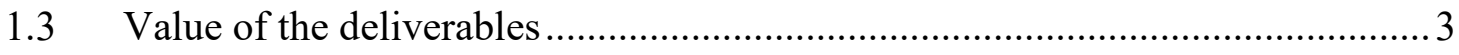

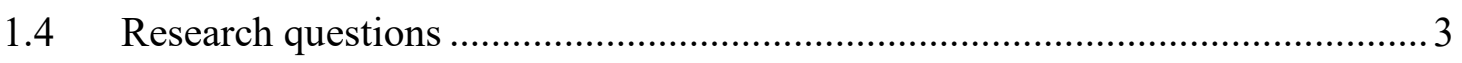

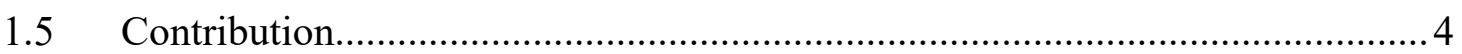

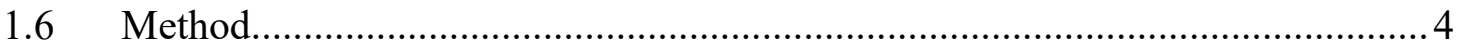

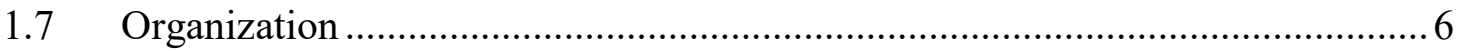

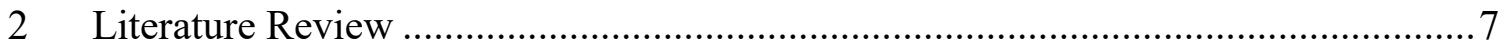

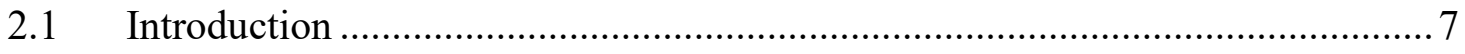

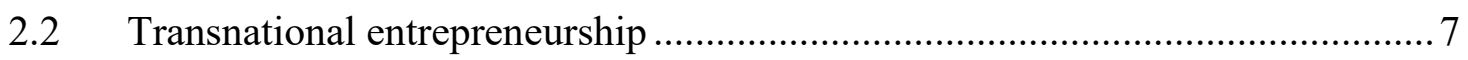

2.2.1 Concept of transnational entrepreneurs................................................ 7

2.2.2 Definition of transnational entrepreneurs ............................................... 8

2.2.3 The motivations of transnational entrepreneurs ...................................... 10

2.2.4 Challenges of transnational ventures ..................................................... 12

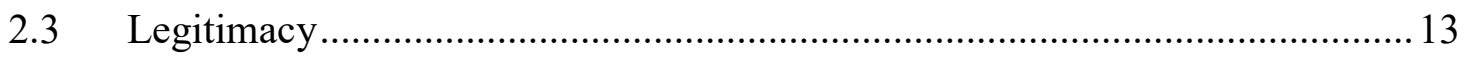

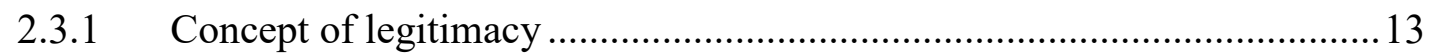

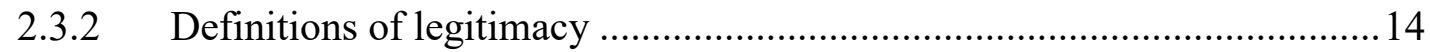

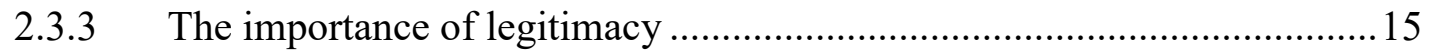

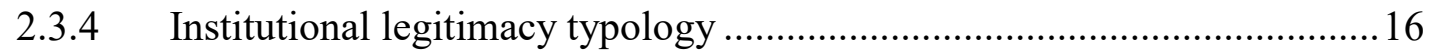

2.3.5 Legitimacy and ventures' liabilities ..................................................... 18 


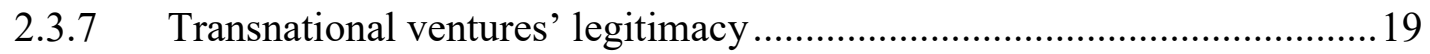

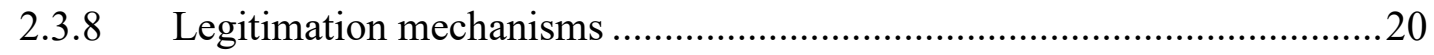

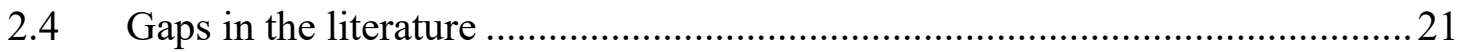

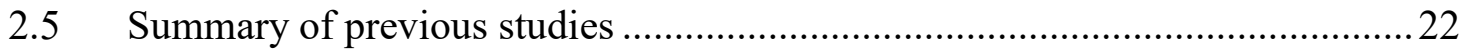

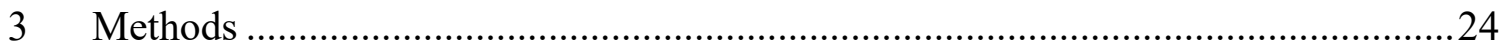

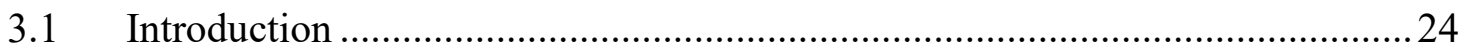

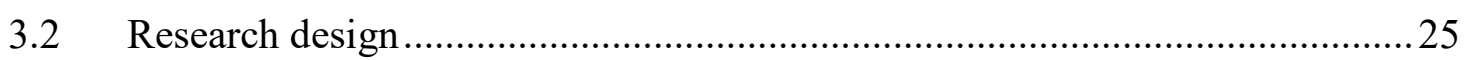

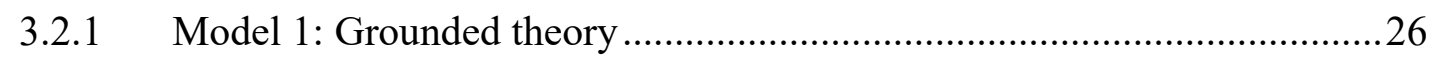

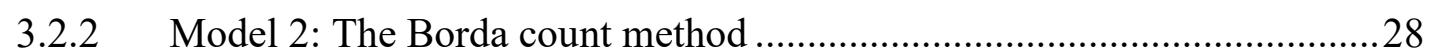

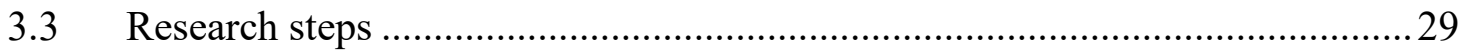

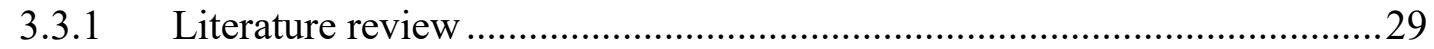

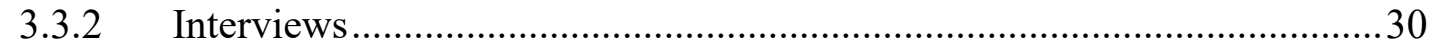

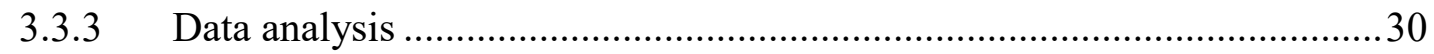

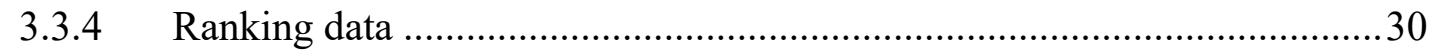

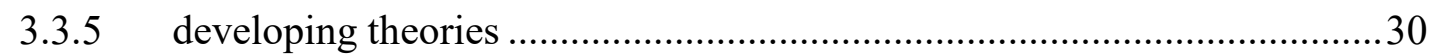

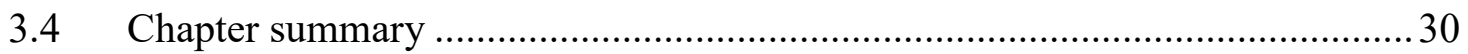

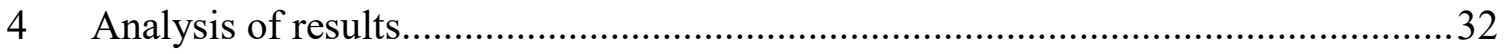

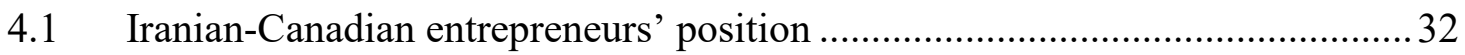

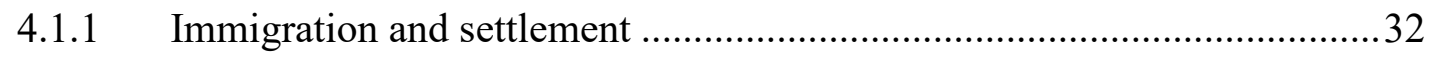

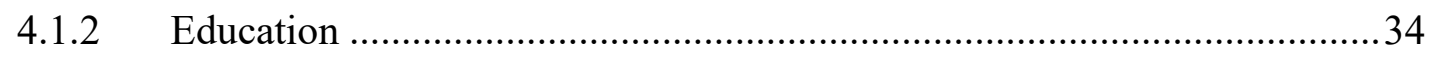

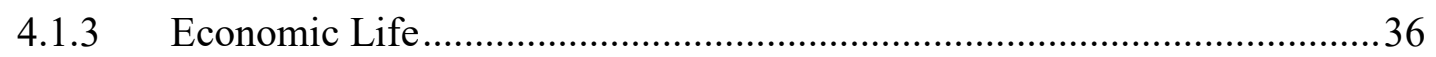

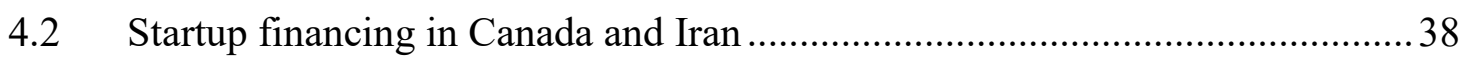

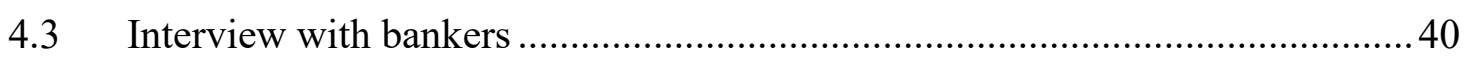

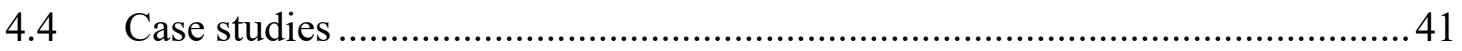




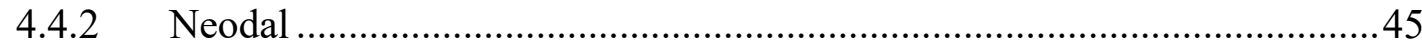

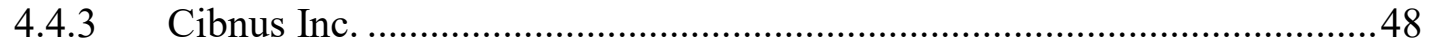

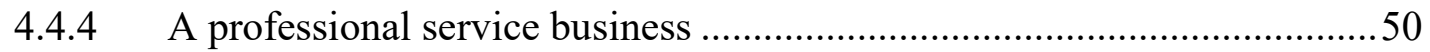

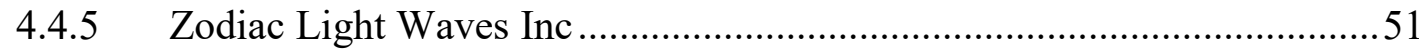

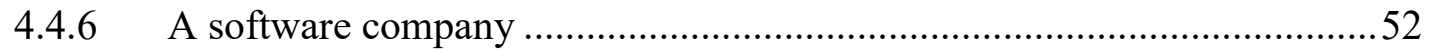

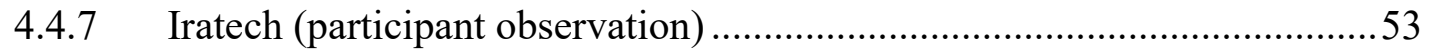

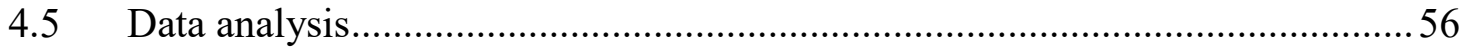

4.6 Borda count method for ranking challenges and criteria ...............................58

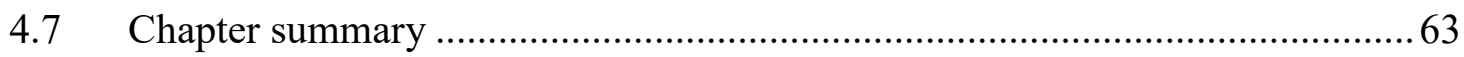

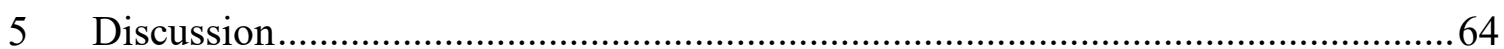

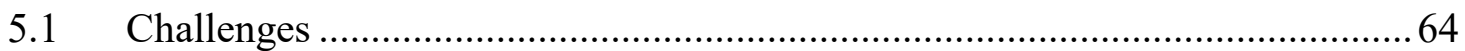

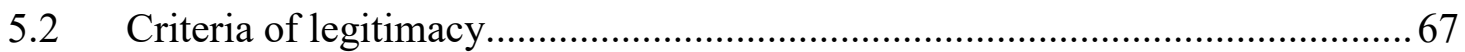

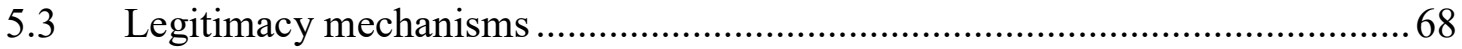

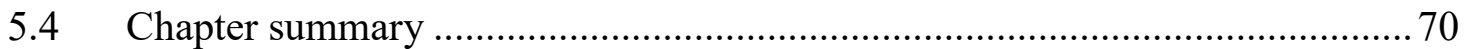

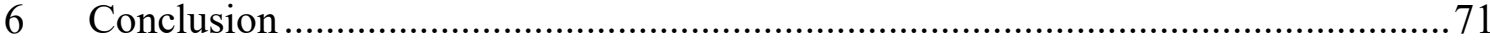

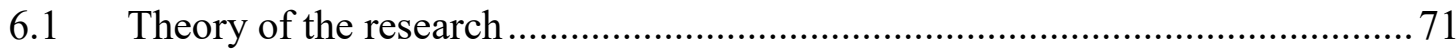

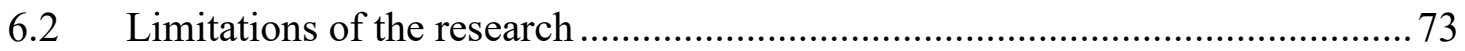

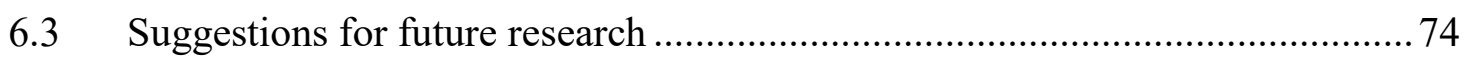

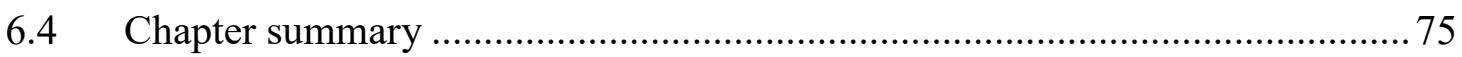

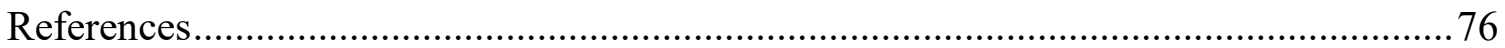

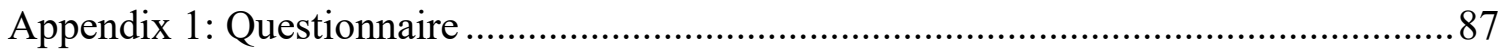

\section{LIST OF TABLES}

Table 1 - Various definitions of legitimacy for new ventures and entrepreneurs.............. 15

Table 2 - Levels of Education among Top Five Immigrant Ethnic Groups in Canada .... 35 
Table 3 - Level of Education Among Top Five Immigrant Ethnic Groups in Canada ....36

Table 4 - Labour Force Aged $\geq 15$ Years by Occupation .37

Table 5 - Employment Income of Population Aged $\geq 15$ Years Who Worked Year-round, Full-time in 2010 .38

Table 6 - The scores and rankings of the challenges of transnational entrepreneurs .59

Table 7 - The scores and ranking of legitimacy criteria from the perspective of banks...60

Table 8 - The scores and rankings of the legitimacy criteria from the perspective of government agencies

Table 9 - Comparison of challenges facing NTVs: Case studies vs. literature 64

Table 10 - Comparison of criteria of legitimacy: Case studies vs. literature. .68

\section{LIST OF FIGURES}

Figure 1- Challenges facing transnational ventures 13

Figure 3- Relationships among the research steps .26

Figure 4- Iranian-Canadians by Age Group .33

Figure 5- Province of Residence for Iranian-Canadians .33

Figure 6- Urban Residents of Iranian Heritage by Province .34

Figure 7- Holders of Postsecondary Certificate, Diploma or Degree (population aged 25 to 64 years) .34

Figure 8- The scores of the challenges of transnational entrepreneurs. 60

Figure 9- The scores of legitimacy criteria from the perspective of banks 61 
Figure 10- The scores of the legitimacy criteria from the perspective of government agencies . 


\section{$1 \quad$ Introduction}

\subsection{Motivation}

According to Cao et al. (2015), since the early 1980s, the firm entry rate in Canada has continued to decline. The country now faces a real challenge, and it must increase its technical innovation particularly in terms of commercialization presentation. Canada has implemented an immigration strategy to attract internationally educated professionals (IEPs) and assist them in building up the country's technological sectors (Lin et al., 2010). IEP-owned transnational businesses could prove helpful for Canada and the countries of origin of the IEP. For example, transnational ventures have provided opportunities for a healthy flow of experience between Canada and China (Lin et al., 2010)

The main challenge that entrepreneurs involved in new ventures face is establishing legitimacy. "Lack of legitimacy may be an obligation to new ventures' leaders that they have to overcome" (Muegge, 2004).

Studying how entrepreneurs make their ventures legitimate has the potential to benefit both the Canadian and the origin country's entrepreneurial ecosystems. Identifying the sources of legitimacy of the two countries, origin and host, would aid the owners of transnational ventures to launch and grow their businesses.

After the 1978 Iranian Revolution, immigration from Iran to Canada and other countries grew dramatically. According to Canadian census records, there was a $28 \%$ increase in the number of Persian-speaking Iranians living in Canada in the period from 1991 to 1996, reaching 62,385 in 1996. Today, Canada remains among the most popular destinations for Iranians seeking to emigrate, and Iranians are the fifth largest subset of immigrants in Canada (Mannani et al., 2002). Many Iranian immigrants have joined the ranks of entrepreneurs and business owners, including an estimated $12 \%$ of those who came to Canada in the $1970 \mathrm{~s}$ 
(Mannani et al.,2002). Iranian immigrants have become involved in various Canadian sectors including construction, food production and bakeries, dry-cleaning, grocery stores, repair shops, computer stores, and so on. Some of the most famous Iranian entrepreneurs in Canada include Karim Hakimi, founder and owner of Hakim Optics; the Ghermezian brothers, developers of the West Edmonton Mall, which is the largest shopping mall in North America; the Khosrowshahi family, founders of the Future Shop chain of electronic and computer stores; and Shahrzad Rafati, founder and CEO of Broadband TV Corp, a digital media and technology company that operates the largest multi-platform network in the world (The 20 World..., 2016).

\subsection{Objective and deliverables}

\subsubsection{Objective}

The objectives of this research are to:

- Identify the sources of legitimacy for new transnational ventures (NTVs) in the eyes of financiers (e.g., banks) and grant providers (e.g., government agencies)

- Identify the process used by entrepreneurs to attain legitimacy for their NTVs from financiers and grant providers.

- Identify the most important challenges NTVs face in the process of gaining legitimacy

\subsubsection{Deliverables}

The deliverables of the research include:

- Criteria used by financiers and grant providers when evaluating the legitimacy of NTVs.

- A list of the main challenges NTVs face when in the process of building legitimacy 
- The explication of the process whereby NTVs demonstrate their legitimacy to financiers and grant providers.

\subsection{Value of the deliverables}

This research has three primary stakeholders: transnational entrepreneurs; resource providers such as investors, financiers, and grant providers; and researchers and graduate students.

Transnational entrepreneurs would find this research useful to their efforts to cultivate an effective strategy for demonstrating the legitimacy of their ventures, with the aim of acquiring necessary resources, support, and/or business opportunities (Fisher et al., 2017; Uberbacher, 2014; Lin \& Tao, 2012).

Resource providers could use the research outcomes and recommendations to develop criteria for assessing the legitimacy of NTVs to make more informed investment and financing decisions (Fisher et al., 2017).

Graduate students and researchers who are interested in transnational entrepreneurship and the question of the legitimate distinctiveness of NTVs would benefit from this study and its suggestions for future research. According to Uberbacher (2014), "[T]he role of legitimacy for new organizations, or 'new ventures' (NVs), has attracted a wealth of research across the management, entrepreneurship, and economic sociology domains."

\subsection{Research questions}

Question 1: Among the various criteria of legitimacy, which are the most important for NTVs to be viewed as legitimate by financiers and grant providers?

Question 2: Among the various challenges of new ventures, which are the most important for NTVs to build legitimacy.

Question 3: What is the effective mechanism to build legitimacy by NTVs. 


\subsection{Contribution}

Canada has implemented an immigration strategy intended to attract internationally educated professionals (IEPs) and assist them in building up the country's technological sectors (Lin et al., 2010). While some studies have found that country policies have only a small effect, others have shown that proactive policies on the part of the host country have a positive impact on recruiting transnational entrepreneurs (Cohen \& Ernesto Amorós, 2017).

Entrepreneurs involved in new ventures need to establish legitimacy. One of the main obligations of entrepreneurs is lack of legitimacy that they should resolve (Muegge, 2004). Therefore, this research intending to pinpoint the most important criteria of legitimacy for NTVs in the eyes financiers and grant providers. The most important challenges NTVs face in the process of gaining legitimacy and the process whereby NTVs obtain the requisite legitimacy to convince financiers and grant providers are other deliverables of the study.

In recent years, studies on transnational entrepreneurship are growing fast (Brzozowski et al., 2017). Plenty of research has been conducted on corporate legitimacy, the legitimacy process and strategy of new ventures, and transnational entrepreneurship. However, to the best of the author's knowledge, there has not yet been any research on the legitimacy of NTVs. This research will contribute to the existing literature by:

- Providing an examination of the intersection of NTVs and legitimacy; and

- Investigating the case of Canadian-Iranian transnational ventures as an emerging market.

\subsection{Method}

The research employs qualitative methodologies including a literature review, participant observation, and in-depth interviews. These steps can be delineated as follows:

Step 1: Reviewing literature 
A literature review will form a very important initial step in this research. As per every research project, reviewing the extant literature enables one to understand previous investigations in the field and to find the other research contribution to the field. In this research, the literature review will also help to model the case studies. The main streams in the literature review will be:

- Transnational ventures (definition, concept, and challenges)

- The ventures' legitimacy (definition, concept, and importance)

- The legitimacy process and criteria for NTVs.

Step 2: Developing a case study model for studying the legitimacy of NTVs.

Several cases will be studied based on a multiple case study model which will be developed in Step 2. The methodology for carrying out case studies will be based on a literature review, participant observation, and in-depth interviews.

Step 3: Developing interview question and conducting the interviews.

Step 4: Developing a model based on case studies to answer the research question.

In this step, the grounded theory method will be used to analyze the data come from the cases and the Borda count method will be employed to prioritize the criteria and challenges that come from the data analysis.

Step 5: Analyzing the cases based on the model developed in Step 4 as well as case study findings

Step 6: Answering the research questions using the Step 5 analysis

Step 7: Conclusion and recommendations. 


\subsection{Organization}

This thesis is organized into six chapters. Chapter 1 provides an introduction to the thesis. Chapter 2 reviews the literature on the legitimacy of ventures and transnational entrepreneurship. In chapter 3 , the research design and methods chosen to achieve the research objectives have been explained. In chapter 4 , the data collected from six case studies as well as two interviews with bank advisors were analyzed. Chapter 5 has discussed the results from chapter 4 in view of the objectives of the research as well as the existing literature. Chapter 6 has detailed the theory that grew out of the research as well as the limitations of the study and suggestions for future research. 


\section{Literature Review}

\subsection{Introduction}

This research has two main streams: "transnational entrepreneurship" and "venture legitimacy". The former is quickly gaining ground as an emerging aspect of International Business (IB) due to increasing migration flows (Gangadhar \& Manohar, 2015). With the increasing entrenchment of globalization and the influence of transnational entrepreneurship on social, political, and economic structures all over the world (Patel \& Conklin, 2009), researchers have found ample avenues of inquiry (Patel \& Conklin, 2009; Drori, Hoing \& Ginsberg, 2006; Portes, Guarnizo \& Haller, 2002).

Building and maintaining trusting relationships is the single most important factor in obtaining legitimacy for new ventures (Muegge, 2004). Ultimately, new ventures must overcome their perceived low legitimacy in order to convince resource providers to provide the necessary support.

In this section, the extant literature will be reviewed with an emphasis on the two main streams of "Transnational Entrepreneurship" and "Corporate Legitimacy".

\subsection{Transnational entrepreneurship}

\subsubsection{Concept of transnational entrepreneurs}

Assimilation, acculturation, and integration are similar concepts that are often discussed comparatively in relation to the concept of transnationalism. However, these concepts vary depending on the political, social, and economic characteristics of the receiving and sending countries (Gangadhar \& Manohar, 2015). As such, before comparing the three concepts, we must first define transnationalism and transmigrants. "Transnationalism" is generally understood to mean the social connections between receiving and sending countries. That is, 
"[t]he processes by which immigrants forge and sustain multi-stranded social relations that link together their societies of origin and settlement" (Schiller et al., 1992).

For example, the act of traversing national borders, which is done by foreign-born residents as part of their daily routines, falls under the definition of "transnationalism" (Portes et al., 2002). Those who forge connections with their settlement countries while also maintaining connections with their countries of origin are defined as "transmigrants". When paired with transnationalism, activities such as entrepreneurship and employment have created a promising route for immigrant wealth creation (Zhou, 2004). Transnational entrepreneurs are able to collaborate economically and socially in their settlement countries while cultivating relationships with family members, communities, institutions, and governments in their origin countries. Examples of social and cultural exchanges include promoting tourism, exchanging education and research, participating in alternative medical publishing, and enriching art, music, film, entertainment, and food (Gangadhar \& Manohar, 2015). According to Portes et al. (2001) "transnational entrepreneurship lies at the intersection of immigrant enterprise, a phenomenon described at length in the sociological literature, and the broader field of transnationalism which includes political and socio-cultural activities as well."

Therefore, transnational ventures can be understood as entrepreneurial organizations in search of opportunities to make use of the resources of host and origin countries.

\subsubsection{Definition of transnational entrepreneurs}

Portes et al. (2002) define transnational entrepreneurs as "self-employed immigrants whose business activities require frequent travel abroad and who depend for the success of their firms on their contacts and associates in another country, primarily their country of origin" 
Similarly, according to Drori et al. (2009), “[T]ransnational entrepreneurs (TEs) are individuals that migrate from one country to another, concurrently maintaining business related linkages with their former country of origin, and currently adopted countries and communities". In short, transnational ventures combine resources from their "dual field and network" to create opportunities and/or optimize resources (Drori et al. 2009). Indeed, Gangadhar \& Manohar (2015) argue that "transnational entrepreneurs are self-employed immigrants who live abroad but maintain strong business linkages with community members in their home countries thereby enhancing their Competitive Advantage.”

When entrepreneurs conduct business between the poles of the host country and their home country, or the country where they currently reside and the country from which they came, this is defined as transnational entrepreneurship. (Decker, 2015). Activities related to international entrepreneurship are carried out in an international context, created and performed by actors, and embedded in at least two different social and economic spheres (Saxenian, 2007). Terjesen \& Elam (2009) maintain that "not all transnational entrepreneurs are immigrants". From an identity point of view, transnational entrepreneurs can be thought of as new "nomads", migrating from one country to another, yet retaining their connections to their countries of origin. Transnational entrepreneurship is culturally oriented, culturally derived, and associated with an individual immigrant's particular community and social relations. Unsurprisingly, transnational entrepreneurs in many countries comprise a very heterogeneous set of ethnic, immigrant, and minority backgrounds, in addition to diverse motivations and experiences (Portes et al., 2002; Wadhwa et al., 2007; Zidon, 2015). Research on international entrepreneurship, however, focuses mainly on organizations and demonstrates very limited engagement with ethnic issues that are not directly related to entrepreneurship (Drori et al., 2006; Yeung, 2002). According to Wong \& Ng (2002), transnational investment is "a business in a national economy that requires separate 
operational components of investing in different countries and the transfer of owners in order to exploit them." In general, transnational entrepreneurship represents a kind of economic transnationalism in which immigrants engage for various purposes.

Two terms that are related to transnational entrepreneurs include immigrant and ethnic entrepreneurs. Whereas immigrant entrepreneurs refer to the first generation of immigrants who were not born in the host country, ethnic entrepreneurs encompass the first, second and further generations of immigrants. Transnational entrepreneurs are immigrant or ethnic entrepreneurs who maintain connections to their country of origin (Brzozowski et al., 2017).

\subsubsection{The motivations of transnational entrepreneurs}

Immigrants often seek opportunities in the host country by starting a business. According to Baltar \& Icart (2013), the factors contributing to immigrant entrepreneurs' decisions to migrate and establish a startup can be categorized as positive motivations and negative reasons. Positive motivations can include job reassignment, business opportunities, better education, new experiences and/or a need for personal change. They identify bad living conditions, unemployment and family reunification in the country of origin as potential negative reasons (Baltar \& Icart, 2013). To some degree, based on the two above-mentioned categories, transnational entrepreneurs can be divided into two groups: "necessity-driven entrepreneurs" and "opportunity-driven entrepreneurs" (Baltar \& Icart, 2013). The first category designates those entrepreneurs who start a business to escape from unemployment or other adverse circumstances, while the second refers to entrepreneurs who are seeking better opportunities (Baltar \& Icart, 2013; Light, 1972; Kloosterman, 2010).

Brzozowski et al. (2017) believe that immigrants' ties have an essential impact on transnational entrepreneurship. They introduce a number of different types of ties that could influence transnational entrepreneurship, including family members and relatives, close friends, ethnic ancestry and ethnic and non-ethnic networks. Both the quantity and quality of 
such ties are important for transnational entrepreneurs' success. Brzozowski et al. (2017) argue that individual characteristics such as age, capital endowment and length of residency in the host country can also play a role in the success of transnational entrepreneurs.

Lin \& Tao (2012) investigated the motivations for immigrating and becoming transnational entrepreneurs in their study of Chinese-Canadian entrepreneurs. They found the following factors to be important motivators for immigrating from China to Canada: income differences, business opportunities, personal career development, environment and health, social security and benefits, child education and family reunification. Motivations for becoming transnational entrepreneurs, according to their study, include: dissatisfaction with one's previous job, lack of promotion opportunities in one's previous position, seeking new business opportunities, extending existing businesses, responding to the requirements of one's employer, trying to make a change, self-challenge, homesickness, wanting to be closer to contacts in China, struggling to adapt to life in Canada and chasing freedom (Lin \& Tao, 2012). Focusing on socio-cultural factors relevant to the development of transnational entrepreneurship, Urbano et al. (2011) studied four entrepreneurs from different ethnic backgrounds in Spain. They argued that socio-cultural factors such as role models and immigrants' entrepreneurial attitudes are important sources of motivation for establishing a transnational business, while transnational networks and understanding the culture and opportunities of the host country were found to facilitate transnational entrepreneurship (Urbano et al., 2011). Similarly, Sequeira et al.'s (2009) study of 1,202 transnational businesses determined that the main determinants of a transnational venture's success are the personal characteristics of the transnational entrepreneur, their social support and the quality of services provided. They also found that transnational entrepreneurs' perceptions of the host country's opportunities and their degree of embeddedness are important factors for success (Sequeira et al., 2009). 
Yoon (2017) notes that while one's network is an important factor that affects both immigration and transnational entrepreneurship, "cultural repertoires" can be even more pertinent to a transnational startup's success. In her study of South Korean and Han Chinese societies, she investigated the "cultural skills" that impact resource mobilization for immigrant entrepreneurs. She found that Korean-Chinese entrepreneurs were very successful in mobilizing resources in both South Korea and China, but their South Korean counterparts were unsuccessful in managing their businesses due largely to cultural and linguistic failures.

\subsubsection{Challenges of transnational ventures}

Aside from the common challenges facing any startup, there are some additional challenges surrounding transnational ventures. For instance, the "shortcomings of relying on networks to mobilize resources" (Chen \& Tan, 2009) has been identified as a challenge due to geographical dispersion. While the effect of ethnic diversity, relational diversity, and embedded resources in transnational entrepreneurship cannot be denied, the dispersion of transnational entrepreneurs' networks does create difficulties. From a geographical perspective, the diversity of these networks necessitates extra effort to maintain and renew such relationships (Chen \& Tan, 2009). Additionally, "cultural and social incompatibility" may emerge when migrants continue the lifestyle of their countries of origin out of habit (Gangadhar \& Manohar, 2015). The "psychosocial challenge", in contrast, may be an issue for entrepreneurs who abandon their countries of origin and especially family members they have left behind (Vertovec, 2004). Lastly, signs of unwillingness to integrate into the new society can be a cause for concern in the host country, potentially even leading to "national security concerns" due to migrants’ perceived loyalty splits (Gangadhar \& Manohar, 2015). 


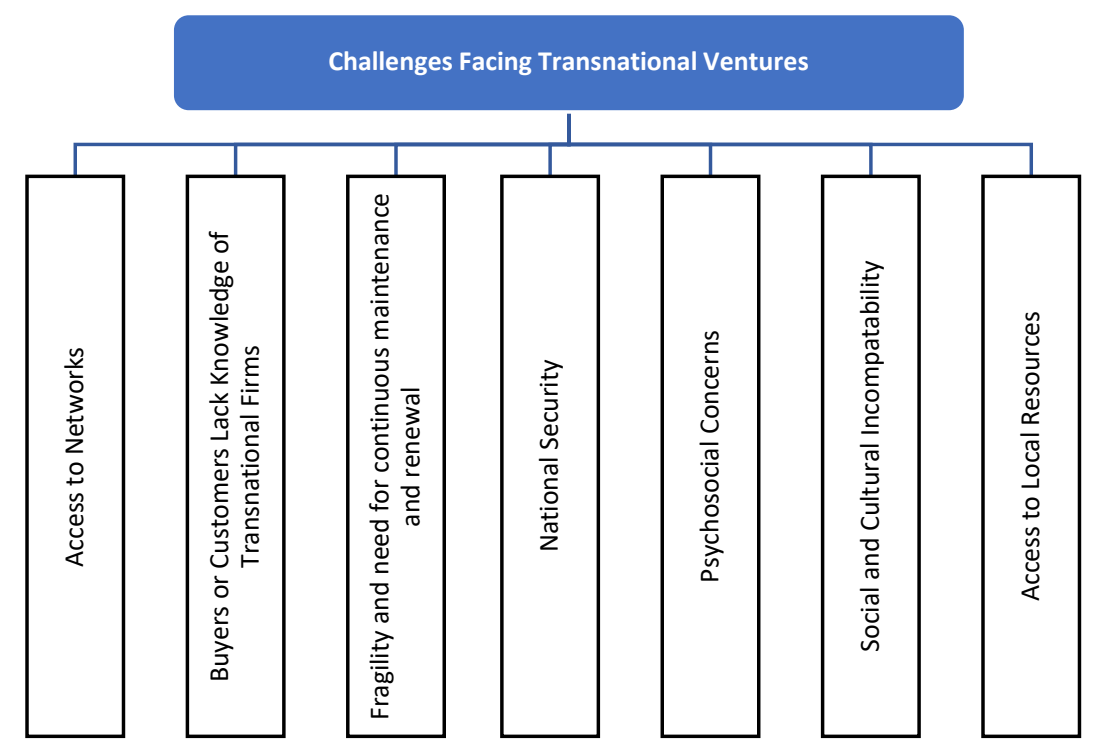

Figure 1- Challenges facing transnational ventures

\subsection{Legitimacy}

\subsubsection{Concept of legitimacy}

According to the Oxford English Dictionary, legitimacy means conformity to the laws or rules, the ability to be defended with logic, and validity. In Persian, legitimacy translates to "Mashroo", which means "Sharia Compliant". However, in an organizational context, legitimacy refers to a venture's credibility in the eyes of external and internal stakeholders, such as financers, employees, and investors (Kuratko \& Brown, 2010). It follows that to be seen as legitimate by stakeholders, a venture's activity must conform to a given country's laws and regulations. In Iran, the concept of corporate legitimacy is the same; however, a venture's legitimacy is also dependent on its adherence to Sharia. Recent studies have focused on inter-partner legitimacy (which is defined as the acceptance of an organization by its network partners), rather than external legitimacy (which is defined as the acceptance of an organization by the broader societal environment) (Human \& Provan, 2000). 


\subsubsection{Definitions of legitimacy}

A number of definitions of legitimacy in relation to new ventures and entrepreneurs have been advanced in the literature, as listed below.

Meyer \& Rowan (1977) define legitimacy as the "adoption of formal structures that are rationalized and institutionalized in a given domain of work activity." Meyer \& Scott (1983) understand legitimacy to be the array of established cultural accounts that "provide explanations for the existence" of an organization. Oliver (1991) simply equates legitimacy to "social fitness." For Suchman (1995), legitimacy is "a generalized perception that the actions of an entity are desirable, proper, or appropriate within some socially constructed system of norms, values, beliefs, and definitions."

Deephouse (1996) and Zimmerman \& Zeitz (2002) take legitimacy to mean "the endorsement", "judgment of appropriateness, acceptance, and/or desirability." of a venture by social actors.

Johnson, Dowd, \& Ridgeway (2006), for their part, posited legitimacy as "[t]he construal of a social object as consistent with cultural beliefs, norms, and values that are presumed to be shared by others in the local situation and perhaps more broadly by actors in a broader community." As Haikio (2007) noted, "Legitimacy means tacit approval.” Kuratko et al. (2010) identify "two major forms of legitimacy as it applies to new ventures": "Conforming legitimacy refers to the certain standards or expectations that become the accepted norms by which firms are deemed legitimate or credible. Strategic legitimacy refers to the actions and behaviors of a firm that lead to business success."

Finally, Tost (2011) defines legitimacy as "[d]eference or obedience to authorities or rules." 
Table 1- Various definitions of legitimacy for new ventures and entrepreneurs

\begin{tabular}{|c|c|c|}
\hline Author(s) & Year & Definition \\
\hline Meyer Rowan & 1977 & $\begin{array}{l}\text { The adoption of formal structures that are rationalized and } \\
\text { institutionalized in a given domain of work activity. }\end{array}$ \\
\hline Meyer \& Scott & 1983 & $\begin{array}{l}\text { The array of established cultural accounts that "provide explanations } \\
\text { for the existence" of an organization. }\end{array}$ \\
\hline Oliver & 1991 & Social fitness. \\
\hline Suchman & 1995 & $\begin{array}{l}\text { "A generalized perception that the actions of an entity are desirable, } \\
\text { proper, or appropriate within some socially constructed system of } \\
\text { norms, values, beliefs, and definitions." }\end{array}$ \\
\hline Deephouse & 1996 & "The endorsement of an organization by social actors." \\
\hline Zimmerman \& Zeitz & 2002 & "A social judgment of appropriateness, acceptance, and/or desirability." \\
\hline $\begin{array}{l}\text { Johnson, Dowd \& } \\
\text { Ridgeway }\end{array}$ & 2006 & $\begin{array}{l}\text { "The construal of a social object as consistent with cultural beliefs, } \\
\text { norms, and values that are presumed to be shared by others in the local } \\
\text { situation and perhaps more broadly by actors in a broader community." }\end{array}$ \\
\hline Haikio & 2007 & Tacit approval. \\
\hline Tost & 2011 & "Deference or obedience to authorities or rules." \\
\hline
\end{tabular}

As can be seen above, each definition emphasizes a different aspect of this concept.

In general, an entrepreneurial venture is deemed legitimate when it appears consistent with the dominant beliefs, norms, and values in its social and cultural environment as well as when its stakeholders consider it appropriate, acceptable, and/or desirable (e.g., Suchman, 1995; Johnson, Dowd, \& Ridgeway, 2006; Zimmerman \& Zeitz, 2002).

\subsubsection{The importance of legitimacy}

Legitimacy plays an important role in shaping stakeholders' views. For instance, new ventures that are perceived as legitimate are considered more predictable, reliable, and significant (Lawrence and Suddaby, 2006). Legitimacy matters because it has the potential to generate active support from clients, resource providers, and even employees, in addition to passive support from the community in which a venture is based (Suchman, 1995). Therefore, the biggest obstacle for a new venture is to demonstrate its legitimacy or credibility to external stakeholders (investors, financiers, employees, etc.). Entrepreneurs must be aware of the 
strategies used to gain legitimacy in the eyes of stakeholders as well as the factors that may influence their perceived legitimacy.

As Chelariu et al. (2014) note, "[T]raditional institutional theory framework assumes that organizational survival and success is determined by attaining legitimacy." Perceptions of legitimacy enable new ventures to overcome their 'liability of newness' and thereby access resources that increase their otherwise low chances of survival (Singh et al., 1986; Stinchcombe, 1965). The process of obtaining legitimacy involves conforming to the patterns, norms, and regulations of a given society, as well as common beliefs held among bankers, suppliers, or even customers (Zimmerman \& Zeitz, 2002).

\subsubsection{Institutional legitimacy typology}

Institutions have jurisdiction over all their operations as well as a variety of structures, carrier cultures, and routine transport institutions. In this conceptualization, institutions are multifaceted systems that incorporate symbolic systems, cognitive constructions, normative rules, and regulative processes carried out through and simultaneously shaping social behavior. Institutions rely on various conveyances and operate at multiple levels, from the world system to subunits of organizations.

According to all typologies, legitimacy includes a number of sub-dimensions. Scott (2007), for example, has mentioned regulative legitimacy (alignment with rules and laws), normative legitimacy (alignment with norms and values), and cognitive legitimacy (alignment with widely held beliefs and ideas, such as cultural scripts, schemas, and identities). Additionally, Suchman (1995) puts forward other sub-dimensions including moral legitimacy and cognitive legitimacy (which are largely congruent with Scott's focus on normative legitimacy and cognitive legitimacy). He also proposes pragmatic legitimacy, which may be based on audiences' self-interested calculations of a venture's value (Suchman, 1995). 
Regulatory processes include the capacity of institutions to establish rules, inspect or review others' conformity, utilize sanctions or punishments, or even distribute rewards to affect future behavior in the future. Scott (2007). Such processes are operationalized through highly formalized activities that are assigned to specific actors, such as police and the courts, or through informal mechanisms including shaming and shunning.

As Scott notes, a second group of theorists places institutions primarily in a normative context. In this case, the focus is on normative rules that introduce prescriptive, evaluative, and compulsory dimensions into social life. Supervisory systems include both values and norms. The former establishes preferences by constructing standards against which structures or behaviors can be compared and evaluated. Standards indicate what must be done; they define legitimacy (legal tools) to pursue valuable goals. From there, oversight systems define goals (for example, winning the game or earning profits), but also determine the appropriate ways to pursue them (for example, fair business concepts).

The cognitive pillar is explained by Scott (2007) as follows: "The third set of institutionalists, chiefly anthropologists such as Geertz and sociologists such as Berger and Meyer and Zucker, emphasize the central and cognitive elements of institutions: The rules that make up the essence of reality and the frames that are made in meaning." Focusing on the cognitive dimensions of institutions is a prominent feature of new institutionalism in sociology, as DiMaggio \& Powell (1991) explicitly point out.

These institutionalists demonstrate a rich understanding of the cognitive dimensions of human existence; the mediation between the world outside the stimulus and the response of the individual organism is a collection of the symbolic embodiments of the inner world. "In a cognitive paradigm, what inventory does is, in essence, the performance of the internal representation of its environment." (D’Andrade, 1984). 
The symbols, words, signs, and motions of your work shape the meanings we assign to objects and activities. By emphasizing the importance of symbols and meanings, we return to Weber's central image. In order to understand or explain any action, the analyst must consider not only the objective conditions but also the actor's mental processes.

\subsubsection{Legitimacy and ventures' liabilities}

If an entrepreneur wants to succeed in launching a new venture, it is imperative to secure resources and support from external actors, including customers and investors. Indeed, Barney (1991) explains that successfully collecting these resources can have a significant impact on the survival and long-term sustainability of a new venture. For members of an external audience to provide a new venture with resources and support, they must first ensure its legitimacy (Fisher et al., 2016; Van Werven et al., 2015; Zimmerman \& Zeitz, 2002). Suchman (1995) believes that an investment is considered legitimate if others call it “desirable, or appropriate within certain social systems, norms, values, beliefs, and definitions." Achieving a perceived state of legitimacy provides ventures with new opportunities to overcome their "debts" and access inputs that will increase their chances of survival (Singh et al., 1986; Stinchcombe, 1965).

Among the studies of new ventures and their potential liabilities, Arthur Steinchkebe's (1965) article on "Structure and Social Organizations" - one of the most cited studies in the history of organizational theory and organizational sociology - may be the most influential and effective. In Stinchcombe's (1965) judgment, new organizations have a tendency to fail and dissolve into constructive organizations. He notes that this innovation responsibility has two main roots, one internal to the venture and the other external (Stinchcombe, 1965). 


\subsubsection{Legitimacy and distinctiveness}

Firms that are similar to other organizations in their corporate environment but are at the same time distinct are well suited to a variety of measures, including organizational productivity (Jennings et al., 2009), asset returns (Norman et al., 2007), and product innovation (Tan et al., 2013). Indeed, research has indicated that the founders of new ventures must convince custodians that their companies are simultaneously situated in their work environment and deprived of other investments and businesses - in this way, a venture's legality is distinguished (Jennings et al., 2009; Navis \& Glynn, 2011). The question then becomes how entrepreneurs can secure such a distinction of legitimacy for their ventures and, more specifically, what verbal strategies they should use for this purpose. To assess the legitimacy of a new activity, stakeholders engage in comparisons between grades to determine whether a given company can be considered a member of a particular category. In

order to make this judgment, stakeholders operate under the assumption that the extent of new ventures is different from that of other ventures in the field. Thus, entrepreneurs face a complex process of persuading stakeholders that their companies are different and at the same time similar to other organizations. To this end, Werven et al. (2014) have developed a cognitive approach grounded in six arguments - argumentation by deduction, classification, generalization, cause, sign, and authority - that entrepreneurs can use to persuade stakeholders, whose investment is needed to render new ventures both legitimate and distinct.

\subsubsection{Transnational ventures' legitimacy}

Establishing legitimacy is crucially important, and it is especially challenging for transnational entrepreneurs. This is in large part due to the fact that their lack of market knowledge leads them to be uncertain about the credibility of their activities, which in turn prevents them from penetrating the market (Miller \& Parkhe, 2002; Zaher \& Mosakowski, 1997). As well, foreign companies are typically unknown among local resource providers, 
such as buyers and customers, and this creates further difficulties for transnational entrepreneurs seeking to market new ventures (Zaheer, 1995; Zaheer \& Mosakowski, 1997). Kostova \& Zaheer (1999) point out that this unfamiliarity could lead to a delay in foreign companies achieving legitimacy because they are more closely examined than domestic firms when they are selected by evaluation partners. Similarly, Miller \& Parke (2002) claim that local resource providers demonstrate a high degree of uncertainty regarding the products or services of foreign companies, and there is a tendency to set higher legal standards for dealings with foreign firms, which leads to further reluctance to conduct trading transactions with foreign capital. All of these factors tied to the local marketplace pose challenges to attaining legitimacy and force foreign companies to come up with solutions to overcome such hurdles. Inter-organizational communication is one feasible potential solution for foreign companies to acquire legitimacy, as a prerequisite for local market penetration.

There are two main points in the intersection of the transnationalism and legitimacy which is unique in the study of transnational ventures' legitimacy. The first is that transnational entrepreneurs have access to resources from at least two countries including the host and origin countries. It may be a source of legitimacy in both countries. The second point is that a transnational ventures' legitimacy in the country of origin does not guarantee the legitimacy of that venture in the host country because the criteria of legitimacy may be different in the two countries for the venture.

\subsubsection{Legitimation mechanisms}

Fisher et al. (2017) propose the following three distinguishable mechanisms for legitimation: "Identity mechanisms", "Associative mechanisms", and "Organizational mechanisms". 
They theorize identity mechanisms as the process of using "cultural tools and identity claims such as images, symbols, and language to strengthen and manage new investment legitimacy" (Fisher et al., 2017).

Meanwhile, associative mechanisms are conceived as the mutual connection between entrepreneurs and their ventures, which shapes ventures' legitimacy and direction. Communicating with other powerful and recognizable actors in a particular sphere (for example, with corporate elites, constructive organizations, prominent investors, etc.) signals to other audiences that the new venture has successfully demonstrated its legitimacy.

Finally, organizational mechanisms are based on the organization and structure of a new venture, along with its measures of success. According to the institutional theory, a new venture is legitimate if it participates in standard behavior or organizational behavior in a given field of activity (Mayer \& Psycho, 1977). Alternatively, a new venture is deemed legitimate if it achieves certain levels of professionalism and performance based on the standard expectations of those within the field (DiMaggio \& Powell, 1983).

In addition, Fisher et al. (2017) note a variety of ways that an entrepreneur can go about improving and managing the legitimacy of a new venture. These include storytelling, feeling, forging relationships, obtaining a certificate, developing a business plan, engaging in Impact Management, and constructing analogs.

\subsection{Gaps in the literature}

As discussed in this section, many researchers are now investigating transnational entrepreneurship and its associated challenges, as well as legitimacy mechanisms and criteria for new ventures. However, thus far no research has investigated legitimacy mechanisms and criteria specific to NTVs. Therefore, this area of research is an interesting topic deserving of targeted study. 
According to Fisher et al. (2017) and Überbacher (2013), the main criteria used by government agencies such as grant providers to evaluate the legitimacy of ventures are the experience and background of the venture's team, the strength of the business and marketing plan, and the venture's potential to contribute to knowledge and provide technological breakthroughs. Although the researcher was unable to locate extant academic research on criteria of legitimacy in the eyes of banks, according to interviews with two bank advisors in Canada, banks consider tax documents that show a venture's revenue and history of paying taxes to be the most important means of demonstrating legitimacy.

\subsection{Summary of previous studies}

To sum up the literature, figure 3 shows the legitimation mechanism including criteria, tools, and processes, kinds of legitimacy and stakeholders for building legitimacy by new ventures.

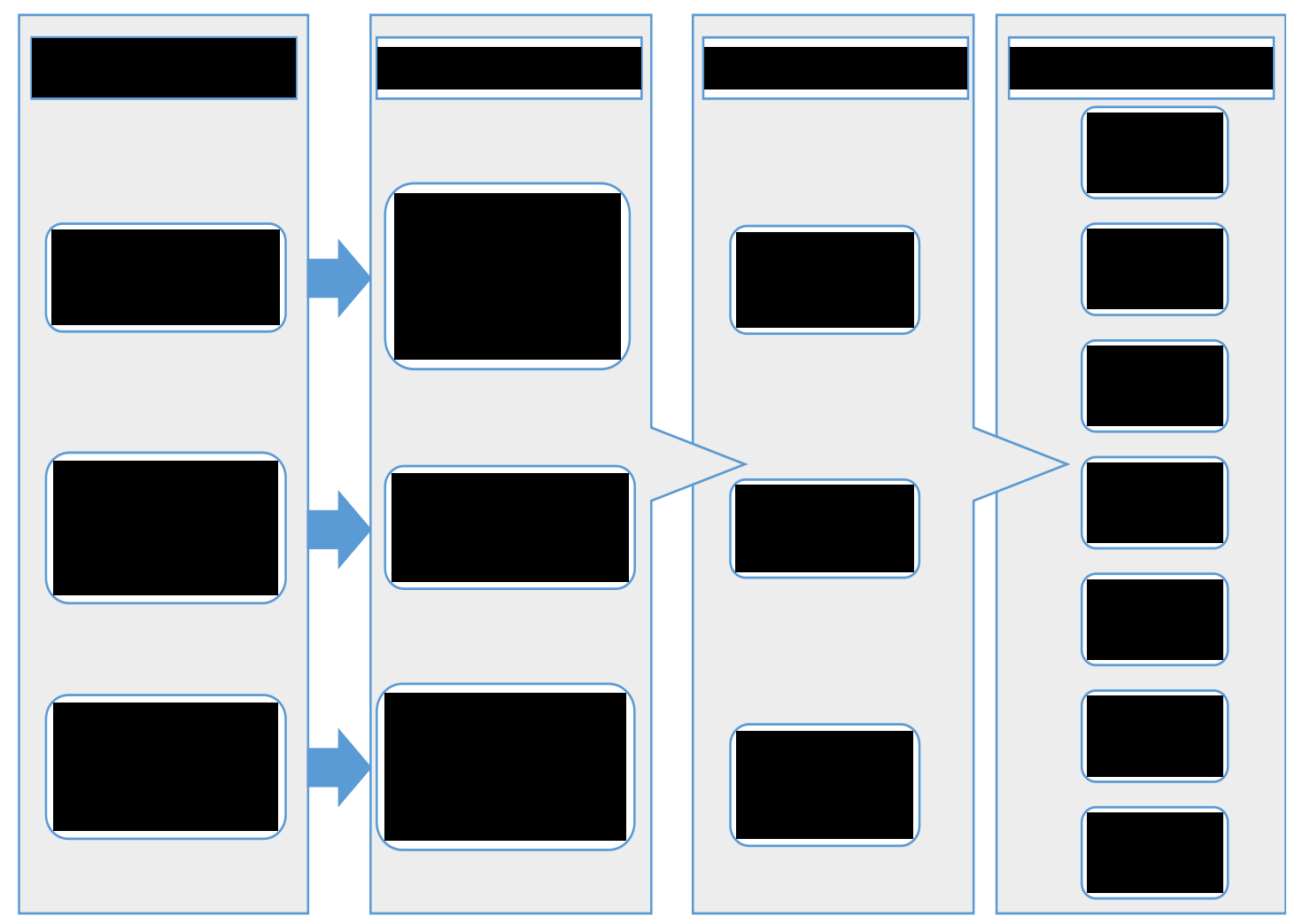


Figure 2- Mechanisms, and their tools for new venture legitimacy evaluation by different stakeholders

According to Fisher et al. (2017) and Überbacher (2013), the main criteria that government agencies such as grant providers use to evaluate the legitimacy of ventures are experience and background of the venture's team, business, and marketing plan, contributing to knowledge and providing technological breakthroughs. The researcher could not find any academic research on the criteria of legitimacy in the eyes of banks, however, according to interview with two bank advisors in Canada, the most important criteria of legitimacy to assess a venture by banks are tax documents and credit history of the owners or the business which show the venture had revenue, has paid tax and has a reputable history in financial discipline. 


\section{Methods}

\subsection{Introduction}

The chief objective of this research is to identify the NTVs' perception of the sources of legitimacy for the ventures. More specifically, the research seeks to pinpoint the most important perceived criteria of legitimacy for NTVs in the eyes of financiers (i.e., banks) and grant providers (i.e., governmental agencies). Insight into the process whereby NTVs obtain the requisite legitimacy to convince financiers and grant providers will be another deliverable of the study. Finally, the research will examine the most important challenges NTVs face in the process of gaining legitimacy.

The unit of analysis is a transnational venture, and the research will employ a combination of qualitative and quantitative methods to determine and ultimately prioritize the legitimacy criteria as well as the challenges of NTVs. Because qualitative methods enable researchers to pursue and analyze data through a particular lens, they are widely used in social and management sciences. As will be explained later in this chapter, the grounded theory as a qualitative analysis used to gather and analyze data. Grounded theory is typically used when there is very little research or existing information about a given topic. It provides researchers with the benefit of straightforward strategies and steps for gathering and analyzing data (Charmaz, 2006). Quantitative methods emphasize the statistical, mathematical, or numerical analysis of data collected using computational techniques. Following the data collection using grounded theory, the Borda count method (Dym, 2002) will be employed as a quantitative means of prioritizing the criteria and challenges, which will also be detailed later in this chapter.

To the best of the researcher's knowledge, there is currently no published research that focuses on the legitimate distinctiveness of NTVs. Therefore, a grounded research methodology, similar to that used by Muegge (2004) and Miller (2006) is well-suited to this 
subject. To achieve the research objectives, six Canadian-Iranian cases will be investigated in order to determine the most important criteria of legitimacy for NTVs in the eyes of two primary audiences, while at the same time examining NTVs' central challenges and mechanisms of legitimacy building.

\subsection{Research design}

After reviewing a variety of commonly used research methodologies, the researcher determined that the combination of qualitative (specifically grounded theory) and quantitative (the Borda count method) methods would be the most suitable for the objectives of the study. The researcher first carried out the qualitative phase of the research to uncover NTVs' challenges and legitimacy criteria before using a quantitative method to rank them.

Grounded theory (Glaser \& Strauss, 1967) uses a rigorous yet flexible approach to develop theory through a detailed analysis of a sociological phenomenon (Miller \& Salkind, 2002).

The Borda count method is conceptually simple and perhaps the easiest means of ranking an entire list of options in order of preference (Saari, 1985).

The primary data sources will be in-depth and semi-structured interviews with six Canadian-Iranian entrepreneurs who have established transnational ventures. Using openended questions, the researcher will investigate the challenges, criteria, and mechanisms associated with demonstrating legitimacy, incorporating probing questions as needed to explore the subject in greater detail. Participant observation, resource providers' websites, transnational ventures' websites, press releases, and independent analysts' reports will serve as the secondary data sources.

Figure 3 shows the relationships among the different steps in the research process, each of which can be categorized into one of four layers: "preliminary study", "Model 1", "Model 
2", and "developing a theory". The aim of the above-mentioned layers is to fulfill the research objectives and answer the research questions.

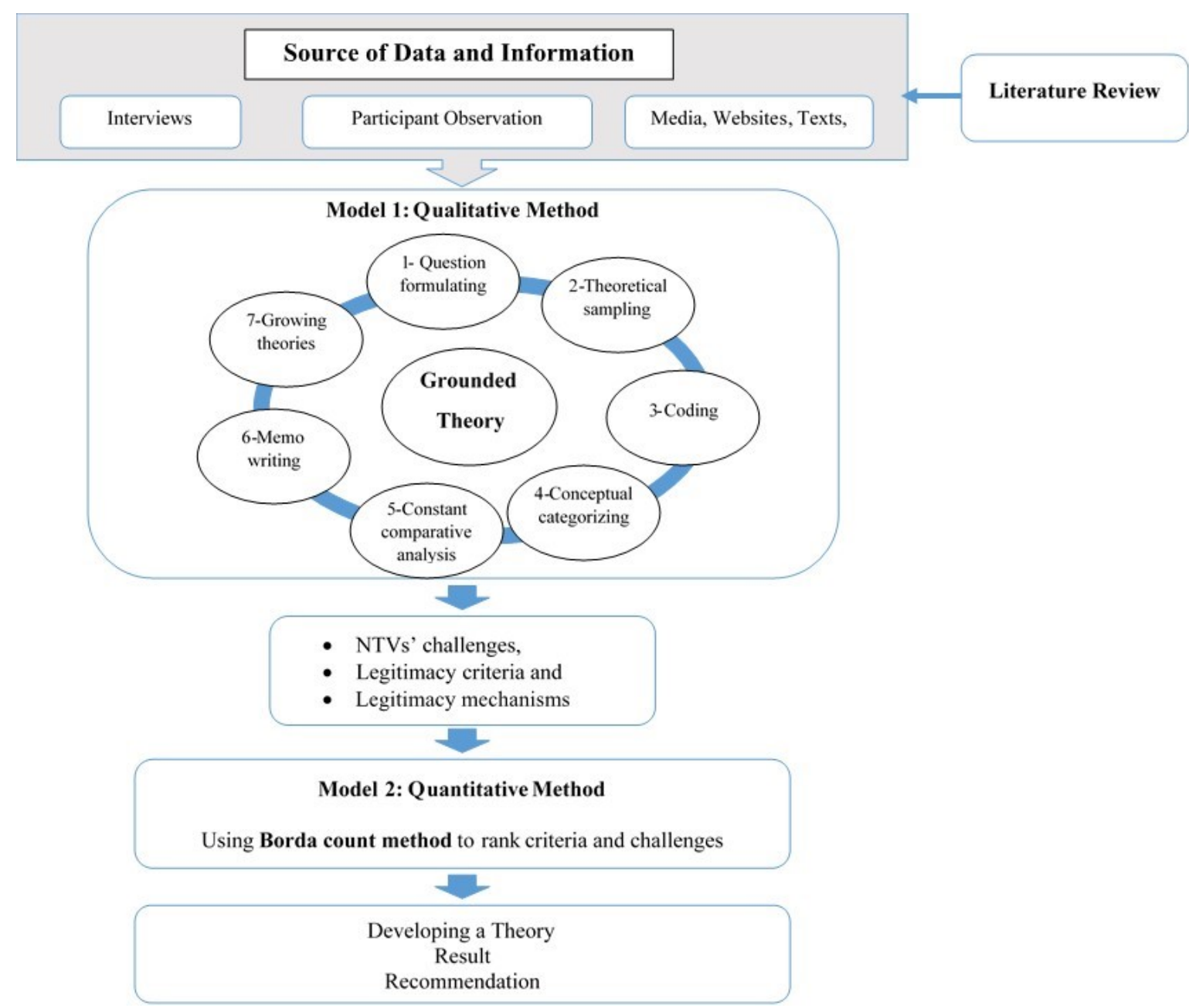

Figure 3- Relationships among the research steps

\subsubsection{Model 1: Grounded theory}

Glaser and Strauss (1967), who developed grounded theory techniques, suggested that researchers investigate processes underlying social phenomena. The purpose of this type of analysis is to gain a new view of a familiar situation, enabling one to assess its applicability to practical problems. Grounded theory has been seen as a systematic methodology for generating a substantive theory relevant to knowledge acquisition (Glaser \& Strauss, 1967).

Grounded theory aims to develop theoretical constructs capable of clarifying the social context under study, generating a combination of both inductive and deductive 
approaches. The term grounded suggests that only through a systematic investigation of a social phenomenon can the researcher extract the conceptual formulations for the data (Glaser \& Strauss, 1967). The generation of theories is the ultimate goal of the research based on grounded theory.

According to Glaser and Strauss (1967), the resulting theory should be (1) theoretically useful, (2) applicable, (3) capable of providing insight into behavior, and (4) able to provide a model for research on specific types of behavior. These purposes form the rationale for theory generation from the data the researcher seeks to explain. Based on this theory, the categories are the result of efforts made to abstract from the data, rather than forcing the data to fit predetermined assumptions.

A study rooted in grounded theory is likely to start with some questions, and the process of gathering qualitative data is then informed by those questions. As the data is reviewed by researchers, repeated ideas or concepts become apparent and are labeled with codes extracted from the data. The collection and review of more data allows for these codes to be grouped into concepts, and then into categories. Based on these categories, new theories can be delineated. Since grounded theory combines data collection and analysis, it differs from other existing theoretical research methods. Namely, it necessitates that the researcher goes back and forth between data collection and analysis in order to "ground" the analysis in the data (Muegge, 2004). The framework suggested by grounded theory also outlines the following concrete steps in the research process (Charmaz, 2006):

- Question formulation;

- Theoretical sampling;

- Coding (data chunking and data naming);

- Conceptual categorizing;

- Constant comparative analysis; 
- Memo writing; and

- Growing theories.

\subsubsection{Developing the questionnaire}

Prior to interviewing transnational entrepreneurs who have established startup ventures, the researcher designed an open-ended questionnaire for the semi-structured interviews. The goal of creating a questionnaire was to minimize interviewer interference by asking each interviewee the same questions. At the same time, this type of open-ended interview reduces the potential for acquiring more comprehensive information from some respondents than others. It also makes it possible to quickly locate each interviewee's answer to a particular question and organize answers that are similar. The questionnaire included three main questions, with a focus on how the NTV obtained sufficient legitimacy to acquire loans or grants from financiers or other resource providers, the most significant challenges faced as a result of being transnational, and the best approach for building legitimacy. Additional questions were incorporated as needed to clarify details about a specific criterion or challenge.

\subsubsection{Theory development}

The grounded theory method requires the researcher to develop a theory in line with the research question(s). Here, theories about the main challenges, legitimacy criteria, and mechanisms for NTVs will be presented at the end of this step. After analyzing the cases and determining the challenges and legitimacy criteria, they will be ranked based on the Borda count method.

\subsubsection{Model 2: The Borda count method}

In 1781, Jean-Charles de Borda developed a weighted method of casting a ballot. Based on Borda's method for ranking $\mathrm{N}$ options (criteria or challenges in this study), points of $\mathrm{N}$ - 
$1, \mathrm{~N}-2 \ldots 0$ are assigned to the first, second ... and last ranked options respectively, in each voter's ${ }^{1}$ order of preference. The sum of points tallied for a specific option determines its final ranking, and the option with the greatest sum of points is considered the most important one (Saari, 1985).

Some advantages of the Borda count method include:

- It is easy to understand and compute.

- The voters (interviewees) are able to express their opinions on various options (criteria or challenges in this study), rather than merely indicating their first choice. Accordingly, an option that is ranked highly but not necessarily first by many voters stands a good chance of being deemed most important when using the Borda method.

\subsection{Research steps}

As Figure 3 illustrates, several steps will be taken to produce the deliverables, and in this section, each step will be explained in further detail. Note that some of the steps can be carried out simultaneously.

\subsubsection{Literature review}

Literature review is an important step in this research. This step conducted constantly during the research. Using the literature review, a questionnaire developed for the interviews.

\footnotetext{
${ }^{1}$ In this research, after extracting a list of challenges and criteria based on grounded theory, the researcher prepared a questionnaire to rank them and sent it to the same interviewees (voters) who participated in the previous step.
} 


\subsubsection{Interviews}

After sending out more than 30 invitations, six Canadian-Iranian ventures selected for the case studies. All cases were among the first generation of immigrants. Using open-ended questions, the interviews conducted with the founder of the ventures.

\subsubsection{Data analysis}

Using the first model in Figure 3, the data from cases analyzed to produce the deliverables of the research. It is needed to be clarified that legitimacy criteria in the view of banks/grant providers are based on the perception of the interviewees, not the banks/grant providers' opinion.

\subsubsection{Ranking data}

The results of the previous step were a list of perceived criteria of legitimacy in the view of banks and grant providers as well as the list of challenges that entrepreneurs faced to obtain legitimacy. In this step, the result of the previous step sent back to the interviewees and ask them to rank the criteria and challenges. They give the highest score to the most important criterion/challenge and one to the least important one. If one criterion/challenge was not a criterion/challenge in their opinion, they gave zero to that. Using a questionnaire with two questions, this step conducted which has explained in chapter 4 .

\subsection{5 developing theories}

Using the results of the previous step, theories of the research developed.

\subsection{Chapter summary}

This chapter has explained the research design and methods chosen to achieve the research objectives. As noted in the methodology section, this study has three main sources of data: textual analysis (including the literature review), interviews with six Canadian- 
Iranian entrepreneurs in Canada (case studies) and two bankers and participant observation. Grounded theory was selected as the method to code and analyze the data collected from the interviews. Finally, after extracting and categorizing the challenges and criteria of legitimacy, the Borda count method has been used to rank the results and determine the most important challenges and criteria. 


\section{Analysis of results}

In-depth and semi-structured interviews, participant observation, and textual material such as resource providers' websites, transnational ventures' websites, press releases, and independent analysts' reports comprise the three sources of data for this research. This chapter will analyze and categorize the data and information gathered from these sources, beginning with a discussion of Iranian-Canadian entrepreneurs' situation in Canada. From there, the researcher will compare the financing of Canadian start-ups with the financing of start-ups in Iran. The final part of the chapter will focus on the six interviews as well as the participant observation.

\subsection{Iranian-Canadian entrepreneurs' position}

\subsubsection{Immigration and settlement}

Compared to immigrants from other countries, Iranians are a relatively new community in Canada. Up until the 1970s, Iranians immigrated to Canada mostly for educational and economic or investment opportunities. Following the Iranian Revolution and during the IranIraq War of the 1980s, however, the majority of Iranian immigrants to Canada were political refugees. Then from 1990 onwards, the predominant motivations of those seeking to emigrate shifted back to economic considerations, as had been the case prior to the Iranian Revolution. Throughout the 1990s, relatively wealthy and well-educated Iranian professionals left Iran to immigrate to Canada (Immigroup, 2017; Rahnema, 2017).

Figures from the 2011 Canadian Census indicate that there were approximately 163,290 Canadians who claimed Iranian ancestry, of whom 83,495 were men and 79,800 women. These figures demonstrated a $34 \%$ growth of the Iranian-Canadian community over a fiveyear period. The census data tables also show that half of the population of Iranian immigrants in Canada were under 35 years of age, with approximately $17 \%$ under the age of 15 and 33\% 
between 15 and 34 (see Figure 4). Overall, 76\% of Iranian-Canadians were between the ages 15 and 64 as of 2010 (National Household Survey: Data tables, 2011). In other words, notwithstanding the differences in legal working ages by province, the overwhelming majority of Iranian-Canadians are of working age.
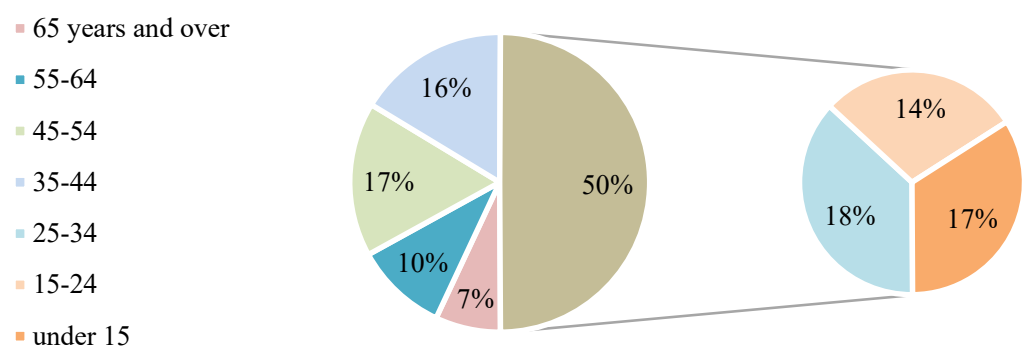

Figure 4- Iranian-Canadians by Age Group

Additionally, as Figure 5 shows, the majority of Iranian immigrants live in Canada's three most populous provinces: Ontario, British Columbia, and Quebec.

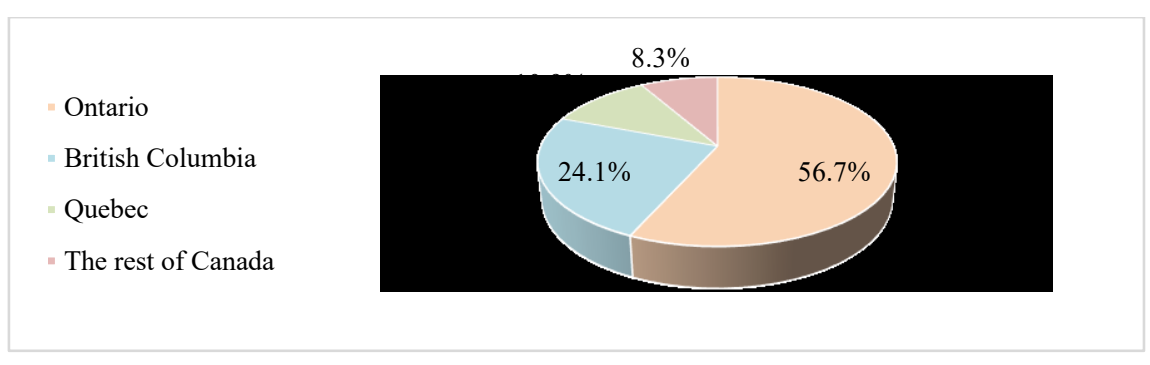

Figure 5- Province of Residence for Iranian-Canadians

Iranian-Canadians also tend to reside in urban areas where there are more economic opportunities for them to take advantage of their professional and/or entrepreneurial skills. The 2011 Census revealed that $79 \%$ of people of Iranian heritage in Canada live in Toronto, Vancouver, and Montreal (National Household Survey: Data tables, 2011), as illustrated in Figure 6. 


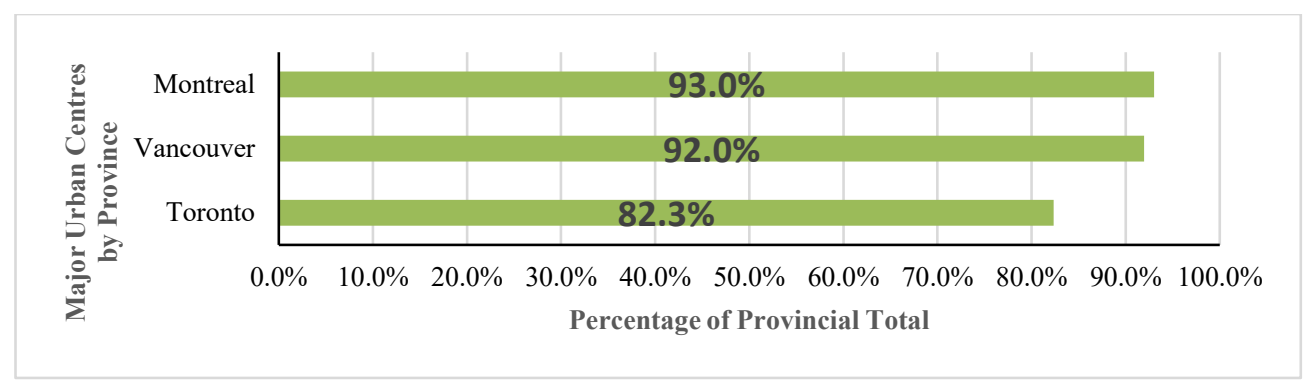

Figure 6- Urban Residents of Iranian Heritage by Province

\subsubsection{Education}

According to the 2011 Census (National Household Survey: Data tables, 2011), IranianCanadians are among the most highly educated immigrant group in the country. In fact, more than one in four Iranian-Canadians aged 25 to 64 hold a graduate degree or similar credential above a bachelor's degree, which is the highest rate among the top five largest immigrant ethnic groups (see Table 2).

More than half of Iranian-Canadians in the 25 to 64 age group hold a University certificate, diploma or degree at bachelor level or above, which is again the highest proportion among the top five immigrant ethnic groups in Canada (see Table 2).

- Apprenticeship or trades

certificate or diploma

College, CEGEP or other

non-university certificate or

diploma

University certificate or

diploma below bachelor

level

- Bachelor's degree

University certificate,

diploma or degree above

bachelor level

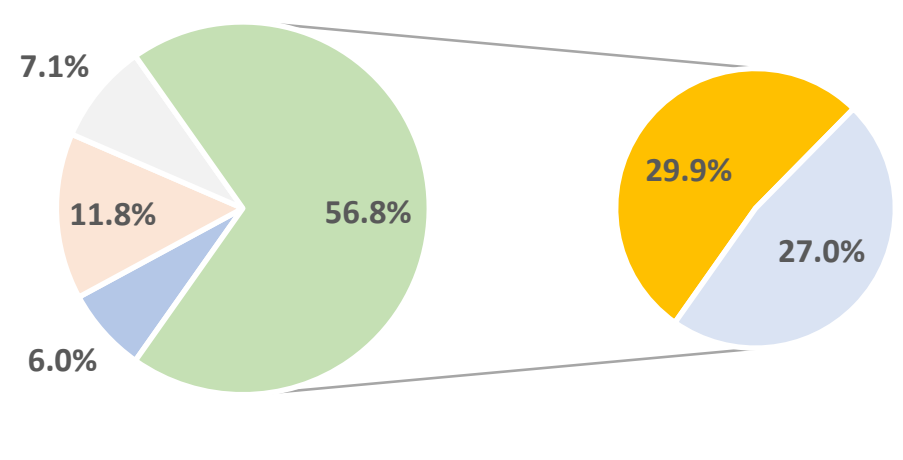

Figure 7- Holders of Postsecondary Certificate, Diploma or Degree (population aged 25 to 64 years) 
Table 2- Levels of Education among Top Five Immigrant Ethnic Groups in Canada

\begin{tabular}{|c|c|c|c|c|c|c|}
\hline \multirow{2}{*}{$\begin{array}{l}\text { Postsecondary certificate, diploma or } \\
\text { degree }^{2} \text { (population aged } 25 \text { to } 64 \text { years) }\end{array}$} & \multirow{2}{*}{$\begin{array}{c}\text { Total for all } \\
\text { Immigrant Ethnic } \\
\text { Groups }^{3}\end{array}$} & \multicolumn{5}{|c|}{ Top Five Immigrant Ethnic Groups } \\
\hline & & Filipino & Chinese & $\begin{array}{c}\text { East } \\
\text { Indian }\end{array}$ & American & Iranian \\
\hline $\begin{array}{l}\text { University certificate, diploma or degree } \\
\text { above bachelor level }^{4}\end{array}$ & $9.4 \%$ & $9.7 \%$ & $15.9 \%$ & $18.8 \%$ & $12.1 \%$ & $27.0 \%$ \\
\hline Bachelor's degree & $16.5 \%$ & $31.4 \%$ & $28.5 \%$ & $22.0 \%$ & $20.1 \%$ & $29.9 \%$ \\
\hline $\begin{array}{l}\text { University certificate or diploma below } \\
\text { bachelor level }^{5}\end{array}$ & $4.9 \%$ & $13.7 \%$ & $8.1 \%$ & $8.1 \%$ & $4.4 \%$ & $7.1 \%$ \\
\hline $\begin{array}{l}\text { College, CEGEP or other non-university } \\
\text { certificate or diploma }\end{array}$ & $21.3 \%$ & $18.4 \%$ & $13.8 \%$ & $14.4 \%$ & $22.1 \%$ & $11.8 \%$ \\
\hline $\begin{array}{l}\text { Apprenticeship or trades certificate or } \\
\text { diploma }^{6}\end{array}$ & $12.1 \%$ & $6.6 \%$ & $4.0 \%$ & $4.8 \%$ & $9.8 \%$ & $6.0 \%$ \\
\hline
\end{tabular}

2 "Postsecondary certificate, diploma or degree" includes "apprenticeship or trades certificates or diplomas," "college, CEGEP or other non-university certificates or diplomas", and university certificates, diplomas and degrees.

${ }^{3}$ This is a total estimated population.

4 The "University certificate, diploma or degree above bachelor level" category includes "University certificate or diploma above bachelor level," "Degree in medicine, dentistry, veterinary medicine or optometry," Master's degree and "Earned doctorate".

${ }^{5}$ Comparisons with other data sources suggest that the "University certificate or diploma below the bachelor's level" category was over-reported in the NHS. This category likely includes some responses of individuals who hold college certificates or diplomas, bachelor's degrees, or have undertaken other types of education (e.g., university transfer programs, bachelor's programs completed in other countries, incomplete bachelor's programs, and non-university professional designations). As such, it is recommended that readers interpret the totals for the "University certificate or diploma below the bachelor's level" category with caution.

${ }^{6}$ The "Apprenticeship or trades certificate or diploma" includes Registered Apprenticeship certificates (including a Certificate of Qualification or Journeyperson's designation) as well as other trades certificates or diplomas such as pre-employment or vocational certificates and diplomas from brief trade programs completed at community colleges, institutes of technology, vocational centers, and similar institutions. 
According to 2011 Census data tables, as shown in Table 4, 81.7\% of Iranian-Canadians aged 25 to 64 held a postsecondary certificate, diploma, or degree, followed by $79 \%$ of Filipino-Canadians, $70.3 \%$ of Chinese-Canadians, $68.5 \%$ of American-Canadians, and $68.2 \%$ of East Indian-Canadians.

\begin{tabular}{|c|c|c|c|c|c|c|}
\hline \multirow{2}{*}{$\begin{array}{l}\text { Level of Education } \\
\text { (population aged } 25 \text { to } 64 \\
\text { years) }\end{array}$} & \multirow{2}{*}{$\begin{array}{c}\text { Total for all } \\
\text { Immigrant } \\
\text { Ethnic Groups }\end{array}$} & \multicolumn{5}{|c|}{ Top Five Immigrant Ethnic Groups } \\
\hline & & Filipino & Chinese & $\begin{array}{l}\text { East } \\
\text { Indian }\end{array}$ & American & Iranian \\
\hline $\begin{array}{l}\text { No certificate, diploma or } \\
\text { degree }\end{array}$ & $12.7 \%$ & $3.5 \%$ & $11.4 \%$ & $11.1 \%$ & $8.6 \%$ & $3.8 \%$ \\
\hline $\begin{array}{l}\text { High school diploma or } \\
\text { equivalent }\end{array}$ & $23.2 \%$ & $16.7 \%$ & $18.3 \%$ & $20.7 \%$ & $22.9 \%$ & $14.5 \%$ \\
\hline $\begin{array}{l}\text { Postsecondary certificate, } \\
\text { diploma or degree }\end{array}$ & $64.1 \%$ & $79.8 \%$ & $70.3 \%$ & $68.2 \%$ & $68.5 \%$ & $81.7 \%$ \\
\hline
\end{tabular}

\subsubsection{Economic Life}

The Iranian-Canadian labor force is dispersed, with no concentration in a particular area of work, and there are no large Iranian businesses that employ substantial numbers of Iranian workers in Canada. Figures from the 2011 Census indicate that more than $50 \%$ of the IranianCanadian labor force aged 15 years and over work in sales and service; natural and applied sciences; management; or education, law and social, community, and government services (see Table 4). 
Table 4- Labour Force Aged $\geqslant 15$ Years by Occupation

\begin{tabular}{lc}
\hline National Occupational Classification (NOC) 2011 & Iranian- Canadians \\
\hline Sales and service occupations & $23.3 \%$ \\
Natural and applied sciences and related occupations & $13.3 \%$ \\
Occupations in education, law and social, community and government services & $12.8 \%$ \\
Management occupations & $12.5 \%$ \\
Business, finance and administration occupations & $12.1 \%$ \\
Trades, transport and equipment operators and related occupations & $8.5 \%$ \\
Health occupations & $7.3 \%$ \\
Not applicable & \\
Occupations in art, culture, recreation, and sport & $4.8 \%$ \\
Occupations in manufacturing and utilities & $2.9 \%$ \\
Natural resources, agriculture and related production occupations & $2.0 \%$ \\
\hline
\end{tabular}

According to 2011 Census data (National Household Survey: Data tables, 2011), more than $15.4 \%$ of Iranian-Canadians aged 15 years and over were self-employed (business owners or entrepreneurs), which was $4.7 \%$ higher than the national average. In addition, the average employment income of Iranian-Canadians in 2010 was slightly above the national average (see Table 5). Indeed, it was found that Iranian-Canadians aged 15 years and over who worked year-round, full-time had the highest rate of employment income among the top four immigrant groups of Asian ethnic origin. Similarly, figures from the 2011 Census also indicate that more than $20 \%$ of Iranian-Canadians aged 15 years and over reported annual total incomes of more than $\$ 50,000$.

${ }^{7}$ This category includes only unemployed persons aged 15 years and over who had never engaged in paid work or self-employment or who had last worked prior to January 1, 2010. 
Table 5- Employment Income of Population Aged $\geqslant 15$ Years Who Worked Year-round, Full-time in $2010^{8}$

Total for all Top Five Immigrant Ethnic Group

Immigrant

Ethnic Groups

Filipino Chinese East Indian American Iranian

Average employment

58,129

45,324

56,934

55,665

64,208

59,387

income in 2010 \$

\subsection{Startup financing in Canada and Iran}

Small and medium-sized enterprises (SMEs) have an important role in the Canadian economy, together employing $90.3 \%$ of private sector workers (10.5 million individuals), as of 2015 (Canada Small and Medium-Sized Enterprises Stats., 2016). Large businesses, on the other hand, employed just $9.7 \%$ of this labor force (1.1 million individuals) (Canada Small

8 "Earnings or employment income" refers to the total income earned by persons 15 years of age and older during the 2010 calendar year 2010. It includes wages and salaries, net income from a non-farm unincorporated business and/or professional practice, and/or net income from self-employment

"Average income of individuals" is the weighted mean total income of individuals aged 15 years and older who reported income for 2010 . The average income is calculated from unrounded data by dividing the aggregate income of a specified group of individuals (e.g., males aged 45 to 54 years) by the number of individuals with income in that group.

The median and average incomes of individuals are calculated for those individuals who are at least15 years of age and who have an income (positive or negative).

The same procedures apply to calculating these statistics for earnings.

"Work activity in 2010" refers to the number of weeks during which a person worked for pay or was selfemployed in 2010, even if only for a few hours, and whether these weeks were mostly full-time (30 hours or more per week) or mostly part-time (less than 30 hours per week) refers to each respondents' age as of their last birthday before the reference date, that is, before May 10, 2011 
and Medium-Sized Enterprises Stats., 2016). "Small businesses were responsible for the vast majority (87.7\%) of net employment change between 2005 and 2015 (1.2 million jobs), compared with $7.7 \%$ for medium-sized businesses and $4.6 \%$ for large businesses" (Canada Small and Medium-Sized Enterprises Stats., 2016). Indeed, as of 2014, SMEs generated an average of $30 \%$ of each provincial GDP, accounting for more than $25 \%$ of Canadian exports in 2013 (Canada Small and Medium-Sized Enterprises Stats., 2016).

Nevertheless, SMEs have an essential role in Canada's economy, however, financing startups and SMEs is a challenging task for entrepreneurs in Canada. According to Small Business (2016), in 2014, more than half of SMEs (51.3\%) sought external financing. A survey conducted by Leung et al. (2008) similarly found that most SMEs in Canada are dependent on individuals' financial situation, including support from family, friends, and others. They found that securing financing for SMEs is more difficult in Canada than in the United States; however, this could simply indicate that Canadian banks follow a more uniform pricing policy than their American counterparts (Leung et al., 2008). According to Canada Small and Medium-Sized Enterprises Stats. (2016), over 80\% of start-ups in Canada relied on personal financing because they were unable to secure grants or loans. The most notable reasons that a startup would be denied bank financing are a lack of a credit history and/or insufficient collateral needed to secure a loan (Canada Small and Medium-Sized Enterprises Stats., 2016).

In Iran, by contrast, SMEs and startups are able to finance themselves through the banking system even if they do not have enough collateral or credit history. The Country Annual Budget Law (CABL) requires banks to finance SMEs and startups based on the economic necessities of the pertinent year. Typically, federal or local governments guarantee some or all of the loan or its interest that will be disbursed by banks, in accordance with CABL. According to what is known as the Tas-hil law in Iran, banks cannot require startups to provide additional collateral beyond what they put into their business, e.g., in the form of 
plants, buildings, and machinery. Therefore, startups in Iran face less financial pressure in procuring bank loans than startups in countries such as Canada. According to the Small and medium-sized enterprises financing (2014), SMEs in Iran received approximately $27 \%$ of all business bank loans in 2012, compared to a rate of $15.7 \%$ for Canadian SMEs (Canada Small and Medium-Sized Enterprises Stats., 2016). Given that corporate financing in Iran is mostly bank based, $27 \%$ of all business loans is quite significant. This shows that compared to their Canadian counterparts, Iranian entrepreneurs rely more on the banking system for financing their businesses, and this is somewhat of a cultural phenomenon.

\subsection{Interview with bankers}

As part of the data collection, the researcher interviewed two Canadian-Iranian banking advisors from two main banks in Canada. Both also had experience working in the Iranian banking system; therefore, they had knowledge of business financing in Canada as well as Iran. Below is a summary of their reflections on startup financing in Canada.

For Canadian banks, loan security is the priority, and to assess this, they conduct two different investigations. The first is based on historical data and information, and the second is based on current and future information. In the first case, banks focus on an applicant's "credit report" and "tax documents". Banks review business and business owners' tax returns for the past two years as well as business owners'/managers' credit reports. The evaluation of these two documents is crucial to reaching the second phase of the process, which is the investigation of the current and future financial status of the business. For gauging the current status, the available capital and collateral are important factors. The higher the capital/collateral, the easier it is to convince a loan officer. As part of the assessment of the future status, business owners must show that their businesses have revenue and that they will 
generate enough revenue in the future to repay the loan. Therefore, a strong business and marketing plan is a very important component of this process.

\subsection{Case studies}

This section will provide an overview of the information gathered from interviews with six Iranian-Canadian entrepreneurs, including five in Ottawa and one in Montreal. Among those interviewed were five entrepreneurs who established their businesses within the past five years and one well-established Iranian-Canadian business owner with more than 20 years of experience in the Canadian business environment.

Drawing from the research objectives, the researcher proposed the following three main questions:

1. What are the most significant challenges for transnational entrepreneurs seeking to obtain legitimacy?

2. What criteria were important to banks/grant providers that evaluated your proposal for financing/funding your business?

3. What are the best steps an NTV can take to attain legitimacy in the eyes of banks/grant providers?

To examine criteria gleaned from the literature review, the following questions were also asked as needed:

4. How important was the experience and background of the venture's team to grant providers/banks?

5. How important was the education level of team members to grant providers/banks? Were Canadian degrees seen as carrying more weight than degrees from other countries?

6. What role do university or city incubators play in helping ventures to obtain legitimacy? 
7. Does being embedded in a university ecosystem help to improve a venture's legitimacy?

8. How important are business and marketing plans to grant providers/banks?

9. How important is the business idea to grant providers/banks?

10. Are there any differences between transnational and non-transnational ventures in terms of the process of obtaining legitimacy in the eyes of grant providers/banks?

The following section presents an overview of the main points that arose from each of the case studies. In accordance with grounded theory, the coded words/phrases have been underlined in the interview summaries.

\subsubsection{Message Hopper}

Message Hopper is a startup located in Ottawa-Kanata that provides a text messaging system for businesses to communicate with their clients. The primary business owner is an Iranian-Canadian with more than 18 years of combined experience in the IT/technology sectors in Iran and Canada. He ran a successful telecommunications company in Iran before immigrating to Canada. As detailed below, the interview spanned a number of topics relevant to this research, including the challenges facing NTVs, the main criteria used by government grant providers and banks to determine legitimacy, and the best process for building legitimacy.

\section{Challenges:}

Message Hopper's primary business owner believed the main challenge for transnational entrepreneurs is funding their startups. According to him, most immigrant entrepreneurs are unfamiliar with the Canadian business environment and the financing opportunities available. For example, because angel investors and venture capitalists are not significant sources of financing for businesses in Iran, many Iranian entrepreneurs may not know of these options. Even if immigrant entrepreneurs do have enough knowledge about the Canadian business 
environment and potential sources of financing, he warned that investors may not trust them as they would a non-immigrant entrepreneur due to their perceived lack of ties in Canada. Therefore, he suggested that transnational entrepreneurs should seek fund from angel investors from their country of origin. Although there are also various grant programs in Canada for startups, determining which one is most appropriate for a specific business venture is a particular challenge for entrepreneurs who are unfamiliar with the Canadian business environment.

He said that a lack of awareness of the cultural norms of the host country is another challenge for transnational entrepreneurs, particularly in terms of knowing how to present a business idea, how to negotiate, and how to market products. He noted that understanding the best time to raise funds is also important for success. For example, if you seek fund during the early stages of your business, you may have to transfer most of your share in the business, as the risk is very high at that time. If you wait to grow your business and then raise capital, you may lose opportunities in the market. While in Iran it is more feasible to seek finance, even from banks, at the first stage of establishing a business, in Canada, knowing the right time to raise capital is very important. Although this not a cultural phenomenon in itself, some immigrant entrepreneurs may not be aware of these norms due to a lack of cultural familiarity. Message Hopper's primary business owner added that insufficient knowledge of the host country's culture may affect transnational entrepreneurs in term of marketing, hiring, and other business logistics. Additionally, selling goods or services in the host country is a $\underline{\text { difficult task for translational entrepreneurs, due to a lack of connections as well as cultural }}$ differences. Cultural differences may also hinder a transnational entrepreneur's ability to effectively present their business idea and engage in negotiations.

Having a weak network in the host country is another challenge for immigrant entrepreneurs, making it difficult to establish trust. Thus, building a network in the host 
country is a related challenge. He explained that when he started his telecommunications company in Iran, he was able to sell his services through his vast network as well as his father's. However, in Canada, he needed to work hard to build connections and then sought marketing help from his network. The interviewee also believes that discrimination is a challenge for minority entrepreneurs. Despite Canada's strict laws against discrimination, he stated that immigrants and non-immigrants do not have equal opportunities.

\section{Legitimacy criteria:}

In term of the most important criteria for building legitimacy in the eyes of banks and grant providers, the interviewee noted the following ideas:

It is difficult to get a government grant before first investing in your business and getting $\underline{\text { it running. He emphasized that even if you have an excellent idea, a strong business and }}$

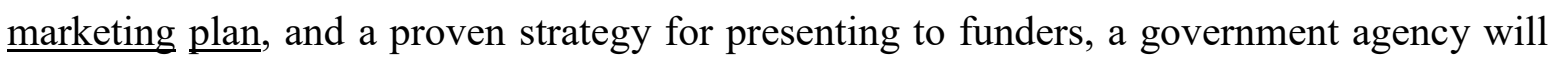
not provide you with a grant if you do not already have your business running. Therefore, as

a first criterion for demonstrating legitimacy to grant providers, you must be able to demonstrate some investment in your business.

Indeed, for most government grants, startups must have investors other than the owner. For example, IRAP prefers startups that have already secured one or more investors, which shows that the risk of failure is low because private investors have strict criteria for investing in a startup.

He advised that an entrepreneur should only seek grant funding once their business has started making revenue. Some funding agencies, such as Invest Ottawa, provide assistance with payroll expenses, in which case a business must already be running and have employees.

The business idea is important to banks, grants providers, and venture capitalists, but even more important for establishing legitimacy is your background and that of your team. Particularly in the IT field, resource providers consider experience to be much more important 
than an entrepreneur's degrees or other educational certifications, according to Message Hopper's owner. Funders must be convinced that a venture has a strong team comprised of individuals specialized in the field, marketing, entrepreneurship, etc.

A business and marketing plan is another important criterion for obtaining legitimacy. Although an immigrant entrepreneur may have an excellent idea and business plan, it is possible that he/she may not present his/her idea and business plan effectively due to cultural differences. Presentation styles are related to cultural habits, and transnational entrepreneurs should thus become familiar with the Canadian style of presenting a business and marketing plan.

\section{Legitimacy mechanisms:}

He also shared his thoughts regarding the process of establishing legitimacy in the eyes of grant providers. More specifically, he outlined three main steps for building legitimacy: 1develop a reasonable business idea; 2 - build a skilled team; and 3- create a strong business and marketing plan. In his view, incubators can be good vehicles for transnational entrepreneurs to gain an understanding of the business environment, develop business and marketing plans, and locate pertinent grants.

\subsubsection{Neodal}

Neodal is a startup located in Ottawa that provides error correction design services for error correction chips, primarily serving software companies and chip producers. The business owner is an Iranian-Canadian IT professional who has been involved in startups in both Iran and Canada for nearly 20 years. He sought business financing from Canadian banks as well as IRAP, and below are the main points he noted in the interview.

\section{Challenges:}

This entrepreneur believes that networking is the chief challenge for transnational entrepreneurs. He said that when he first moved to Canada, it was difficult to find the right 
people to provide him with information. Eventually, he sought help from a friend in Iran, and they connected him to the Iranian community in Ottawa, which provided him with an initial network. He explained that the best and most convenient way to build a network is by relying on your existing network in your country of origin as well as immigrant communities from your country of origin in the host country.

Securing funding for one's business is another challenge for immigrant entrepreneurs. While funding is a challenge for all startups, it may be more difficult for transnational startups, particularly if the host and origin countries have different common of financing businesses. For instance, entrepreneurs in Iran mostly seek finance from friends and banks, but these sources may be unavailable or inadequate in the Canadian context. Additionally, competition is high among startups, which makes finding sources of financing a very challenging task. The situation in Canada is much more competitive now than it was several years ago.

The interviewee explained that because his startup is in a complicated hi-tech field, it is likely only understood by experts. Thus, for very hi-tech ventures, the problem of building legitimacy is amplified by the fact that potential investors may not understand the business proposal.

He sought help from IRAP, but after a while, he realized that the funding would only cover a small portion of the total expenses needed to start the business. Therefore, he advised that IRAP funding should not be relied on to finance a business, but rather to help boost an existing business.

Neodal's owner also suggested that cultural differences and insufficient knowledge of the host country's business environment may be challenges for some immigrant entrepreneurs. Due to misunderstandings, he said that some transnational entrepreneurs may feel that they are discriminated against when seeking fund. According to him, some immigrants assume 
that if they have an idea and go to a developed country, the significance of their idea will immediately be understood and the system in the host country will provide them with a great deal of support. In reality, they do not have a sense of the competition involved or the limited nature of available resources. Such misunderstandings are partly the result of transnational entrepreneurs being unfamiliar with the host country's business environment, while cultural differences between the host and origin countries also play a role.

\section{Legitimacy criteria:}

When asked about the main criteria that grant providers and/or banks use to evaluate the legitimacy of NTVs, he said that banks mostly base loan decisions on the business plan. However, they also need to secure the loan, and this can be done through collateral. Therefore, he noted that even if you have a strong business plan, banks will not offer you a loan unless you provide collateral or another means of securing the loan, such as a credible co-signer.

If $\underline{\text { someone else invests in your business, }}$ he said that this helps you to obtain legitimacy in the eyes of banks and grant providers. Because banks and government grant providers seek to avoid being the first risktaker, they are more likely to view your startup as legitimate for financing if you have already convinced an angel investor or venture capitalist to invest in your venture.

In most cases, your business must already be running in order to be eligible for funding or financing. For example, IRAP funding mostly goes towards your payroll costs; therefore, you must have already invested in your business and the business must be running.

Regarding degrees and other educational credentials, he believes that banks and grant providers do not consider the educational qualifications of an entrepreneur or other team members to be important factors for determining legitimacy. 
In his opinion, the experience of the team and the business owner is far more important to banks and grant providers. They must be convinced that the team has the necessary skills to run and expand the business.

\section{Legitimacy mechanisms:}

There are some important steps and procedures that every startup should follow to build legitimacy. Aside from those, he advised that having an understanding of the culture and business environment in the host country is essential for immigrant entrepreneurs and should be the first step for NTVs hoping to obtain legitimacy. In his experience, the best source for helping new immigrants to adapt to the host country's culture and business environment is the community of fellow immigrants from one's country of origin, especially those who have spent many years in the host country and know both environments well.

Developing a strong business and marketing plan marks another important step towards building legitimacy in the eyes of banks and grant providers. Communities in Canada that share one's country of origin may also be able to help prepare a strong business plan based on Canadian style conventions and to present it effectively.

\subsubsection{Cibnus Inc.}

Cibnus Inc. is an Ottawa-based business in the food sector that was established in 2013 as a producer and has since expanded its business to export agricultural products to Iran. The company's founder is an Iranian-Canadian student who sought a business opportunity that would make use of his vast network in his country of origin by producing agricultural products and exporting them to Iran. On the Canadian side, farmers, elevator owners, grain dealers, and transloading and shipping companies are among the company's main stakeholders. The business owner did not apply for any grants from government or nongovernment agencies, but he did approach several banks for financing. Below is a summary of the business owner's experience working with Canadian banks to finance his business. 


\section{Challenges:}

The owner of Cibnus believes that funding the business is the main challenge for NTVs, noting the potential difficulties associated with building legitimacy in the eyes of banks. As part of their financing conditions, he explained that almost all banks require businesses to demonstrate a sustained presence in the market as well as a large amount of capital invested by business owners. Given the need for specialized knowledge of Canadian bank policies and certain legal restrictions in the Canadian banking system, translational ventures may face more challenges in this regard. Also, he mentioned that there are certain stereotypes that make it more difficult for some minorities to do business in Canada.

\section{Legitimacy criteria:}

Some of the very first questions asked of him by banks were those pertaining to the experience and background of the founder and director of the business. However, he added that for Canadian banks, a founder's capacity to successfully do business plays a minimal role when compared to the importance of their available cash.

As for academic degrees being seen as a criterion for legitimacy, he believed that a university degree is not important to banks. Indeed, he said that to some extent, entering the market with an advanced university degree, especially a Ph.D., might even be considered a disadvantage. In his experience, business and marketing plans are not that crucial from the perspective of banks. He observed that it seems banks try to avoid spending their human resources and time to evaluate business plans; instead, they evaluate businesses primarily on the basis of their available capital.

\section{Legitimacy mechanisms:}

In his view, maintaining a presence in the market for several years and securing a large amount of capital for your business are the two most important means of acquiring legitimacy in the eyes of banks. 


\subsubsection{A professional service business}

The next interview was conducted with a professional service business in the field of immigration law and paralegal services that would prefer to remain anonymous. This business was established in Ottawa two years ago and then expanded its services to Vancouver, which has a much larger population of Iranian-Canadians. The business owner is an IranianCanadian who immigrated to Canada in search of business opportunities. Most of the company's clients are Iranian-Canadians, and the owner has experience working with Futurpreneur as well as banks to finance the business. He has a credit card and a line of credit with banks for his business. His experience with building legitimacy is outlined below.

\section{Challenges:}

Initially, problems with his credit score made it very difficult for him to get grants and financing. He felt that transnational entrepreneurs lack knowledge regarding how to build a positive credit history, which poses challenges for financing their businesses.

Another challenge that he encountered when trying to apply for grants was not knowing how

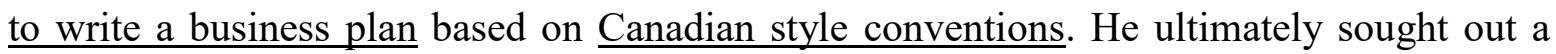
qualified person within the Iranian community in Ottawa to do this for him. Therefore, preparing and presenting business and marketing plans may be a challenge for immigrant entrepreneurs.

\section{Legitimacy criteria:}

Based on his experience, he said that the business and marketing plan is the first criterion considered by both banks and Futurpreneur to determine whether an NTV has legitimacy. Yet, while the business and marketing plan is an important criterion, for banks an excellent

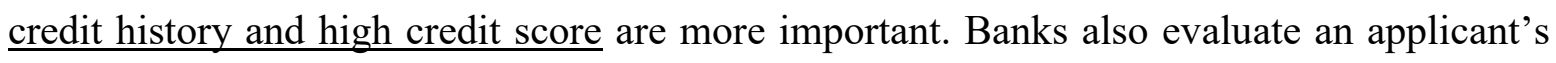
tax records and history of paying taxes, but this is not important to Futurpreneur. 
As this business provides professional services that are regulated, Canadian licenses, as well as Canadian degrees, are necessary. In cases such as this, $\underline{\text { Canadian credentials }}$ are an important criterion for both banks and grant providers.

\section{Legitimacy mechanisms:}

To build legitimacy, he said that a transnational entrepreneur must:

- Build a positive credit history;

- Develop a strong business and marketing plan; and

- Secure a Canadian university degree, if relevant to one's sector.

\subsubsection{Zodiac Light Waves Inc}

Zodiac Light Waves Inc. is a well-established transnational company located in Ottawa, with more than 20 years of activity in the market. The business developed a Wireless Nurse Call system and provides network security and telephone services for retirement communities as well as the long-term care industry. The founder is an Iranian-Canadian entrepreneur who has experience working with banks as well as IRAP. By way of comparison to the other case studies, the researcher sought to gain insight from the owner of a well-established business who successfully launched and expanded a company. The main points made in this interview are as follows:

\section{Challenges:}

The owner of Zodiac has more than 20 years of experience in the Canadian business environment. Based on his experience establishing his business and helping other immigrants to run their businesses, he has seen no difference between transnational and non-transnational ventures in terms of obtaining legitimacy in the eyes of grant providers/banks. However, he emphasized that understanding the culture and language of business as well as gaining a knowledge of the rules of the game in the host country are the most significant challenges for NTVs. 


\section{Legitimacy criteria:}

Regarding the main criteria of legitimacy in the view of banks, he mentioned loan security and the financial integrity of the team as the most important factors. While he believed that the team's experience is important to banks, he said that they mostly care about the security of the loan. He explained that this was in contrast to IRAP, which considers the experience and knowledge of the team more important than other factors.

Another important criterion that he addressed is the business plan. The business and marketing plan is very important to both banks and government grant providers. In his experience, a strong presentation of one's case for a grant is given more weight than the educational credentials of the team. Whether dealing with banks or government agencies, he advised that those evaluating the plan must be convinced of a foreseeable return on the potential money they would invest.

In the case of government agencies, he said that the most important parameters are the team's experience, the business model, and the research plan. An innovative idea is also important to IRAP as well as most government grant providers. According to him, banks too are interested in new ideas, but they ultimately need security for their money.

\subsubsection{A software company}

The next interview was conducted with the owner of a software company in Montreal that would prefer to remain anonymous. This business is a virtual recruiter powered by artificial intelligence techniques. Its target market is engineering recruiting, and its target clients are businesses of all sizes in need of hiring engineers. The business owner is an Iranian immigrant who came to Canada to pursue entrepreneurial opportunities in the IT field. Below is a summary of his experience and thoughts regarding the process of building legitimacy in the eyes of Canadian grant providers and financiers.

\section{Challenges:}


He believed that potential differences in the level of professionalism, work ethics, and quality of education between immigrants' origin and host countries can create a significant challenge for transnational entrepreneurs looking to start a business. Such inconsistencies may be the result of cultural differences or variations in laws and regulations. Beyond this challenge, he said that the other challenges are the same for transnational and nontransnational ventures.

\section{Legitimacy criteria:}

The business owner believed that one of the most important criteria for both banks and grant providers is the business and marketing plan. He also cautioned that when he attempted to get grants, his business was not qualified because he had not provided enough initial investment. To qualify for most grants, a business must already have some investment from the owners or other investors. Based on his experience, it is not possible to rely on bank financing to start a business in Canada, largely because businesses must be able to demonstrate a long-standing presence in the market to qualify for a loan.

He added that another important criterion is your team. Both banks and grant providers must trust your team and be convinced that your team is sufficiently qualified to lead the business to success.

When asked about the importance of having an innovative idea, he said that this was not an important criterion for legitimacy from the perspective of banks and grant providers. In his view, they care much more about having clients and making money.

\subsubsection{Iratech (participant observation)}

Iratech is an e-learning business that provides professional training by connecting learners in developing countries, with a focus on Iran, to educators in developed countries such as Canada. The business was started in Ottawa with help from the Carleton TIM program and the Lead To Win (LTW) incubator. Iratech is owned by an Iranian-Canadian TIM student 
who has worked with LTW, Invest Ottawa, Ottawa World Skills, and banks in Canada and Iran to help launch and finance the business. The main points noted during the participant observation portion of the research are detailed below.

\section{Challenges:}

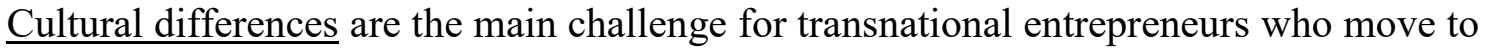
a new country and must adapt to a different culture. Having an awareness of the host country's culture and acting in accordance with the cultural norms is important for succeeding in business. As a new immigrant to Canada, the researcher had difficulties presenting his idea in front of grant providers. After getting help from the TIM program and presenting the idea at LTW three times, the researcher discovered that part of the problem was related to cultural differences.

There are also a number of other challenges that may affect the ability of transnational immigrants to demonstrate the legitimacy of their businesses. For example, not having an adequate network in the host country is one of the main challenges. A transnational entrepreneur's network in their country of origin can be a helpful means of overcoming this obstacle to establishing and growing a business, particularly in terms of marketing one's business. Therefore, the researcher developed a business that would primarily serve clients in his country of origin. Still, the subsequent distance from the market created another challenge. A lack of knowledge about the Canadian business environment and being unfamiliar with the $\underline{\text { language of business }}$ were other challenges encountered in establishing Iratech. For example, when the researcher needed to negotiate with a funding provider in Toronto, he sought help from a friend who had lived in Canada for more than 20 years and was familiar with the Canadian style of business negotiation.

\section{Legitimacy criteria:}


Based on the researcher's negotiations with three banks, the most important criteria of legitimacy are records of revenue/tax paid for at least the previous two years, a high credit $\underline{\text { score, }}$ and collateral or capital.

In the eyes of grant providers such as Invest Ottawa, Futurpreneur, and LTW, the researcher found the main criteria of legitimacy to be: an innovative idea that can lead to products; a strong business and marketing plan; the level of employment (i.e., how many people your business will employ); the capacity of the business to generate revenue in the future; and the team's experience and knowledge. The first factor that each of the above grant providers considered was the anticipated future revenue of the business. Grant providers must be convinced that the business can generate revenue and grow into a medium/large-scale business. Accordingly, the business plan is very important.

\section{Legitimacy mechanisms:}

As mentioned earlier, cultural differences are the most significant challenge for immigrant entrepreneurs. However, in working with incubators and immigrant settlement organizations such as LTW, Invest Ottawa, and Ottawa World Skills, as well as through textual analysis and interviews with other immigrant entrepreneurs, the researcher has found government agencies and incubators to be good sources for basic training on entrepreneurship, the Canadian business environment, business language, and developing business plans. In addition, university ecosystems and university incubators can provide help to both develop a strong business and marketing plan and learn how to effectively present it in front of potential investors. Incubators, especially in the university ecosystem, may also be able to provide some funds and additional support such as marketing, legal, and accounting services that can help a startup test out their idea.

To grow your business, you need to find investors. The best way for a transnational entrepreneur to find investors is to reach out to their country of origin community in the host 
country. Shared cultural norms make the process of convincing angel investors from one's own country of origin much more straightforward. In other words, it is often easier to appeal to a potential investor who shares your background than an investor from the host country.

To be successful as a transnational entrepreneur, it is crucially important to build a network in the host country. To start, it can be helpful to network with local communities connected to one's country of origin, such as the Persian Art and Cultural Society of Ottawa (PACSO), or even immigrant organizations such as Ottawa World Skills. To secure bank financing, startups must have collateral and be able to demonstrate that the business already generates revenue. That is, startups must generate revenue before applying for bank financing to grow the company.

\subsection{Data analysis}

As mentioned earlier, the researcher used an iterative process to evaluate the interviews, coding the main ideas with reference to the literature as well as interviewees' points of emphasis. Repeated ideas or concepts have been highlighted by underlining them in the text, for example. Phrases such as "the main challenge for transnational entrepreneurs is funding", "transnational entrepreneurs do not have enough ties in Canada", and "transnational entrepreneurs are unfamiliar with the Canadian business environment" were listed as preliminary groupings. Repetitive, overlapping, and vague expressions were eliminated or presented in more descriptive terms on an ongoing basis as the interviews continued. As well, each statement was tested to determine whether the phrase could be labeled with a code. Then the codes were grouped into concepts, and finally into categories.

The following categories were identified during the interviews and have been grouped according to each research question: 
Research Question 1: What are the main challenges for transnational entrepreneurs in obtaining legitimacy?

- Cultural differences

- Lack of strong ties

- Procuring funding

- Building a network

- The market and competition

- Unfamiliarity with the Canadian business environment

- Lack of knowledge of Canadian banks and legal restrictions

- Preparing an effective business \& marketing plan

- Insufficient understanding of Canadian business language

- Difficulty communicating hi-tech ideas

- Discrimination

Research Question 2: Among the various criteria of legitimacy, which are the most important for NTVs to be viewed as legitimate by financiers and grant providers?

- Amount of owner investment

- Amount of investment by other investors

- Being in the production phase or having the business running

- Experience \& background of the founder and director

- Strong business and marketing plan

- Excellent credit history and high credit score

- Tax documents and history of paying tax

- Number of employees

- Loan security 
- Innovative idea

Research Question 3: What are the legitimacy mechanisms whereby NTVs can demonstrate their legitimacy to financiers and grant providers?

1. Gain an understanding of the host country's business environment and business language. Government agencies, university ecosystems, incubators, and individuals from one's country of origin who have lived in the host country for many years can help in this regard.

2. Develop a strong business and marketing plan.

3. Build a skilled team.

4. Find an investor external to your business. It may be easier to secure a venture capitalist from one's country of origin than investors from Canada or other countries.

5. Maintain a presence in the market for several years and build up the company's capital and annual revenue.

\subsection{Borda count method for ranking challenges and criteria}

After analyzing the data and determining the primary challenges and legitimacy criteria, the researcher ranked them based on the Borda count method. For this purpose, a questionnaire containing three questions was used (see Appendix 1) to enable the interviewees to prioritize the challenges NTVs face as well as the legitimacy criteria from the perspective of banks and government agencies. The researcher then calculated the score for each factor. For example, "cultural differences" as a challenge facing NTVs was variously ranked first, fourth in two instances, eighth, ninth, and tenth by the six respondents. Therefore, the score for that challenge was calculated as follows:

Number of challenges: $\mathrm{N}=11$

Score of "cultural differences" $=1 *(11-1)+2 *(11-4)+1 *(11-8)+1 *(11-9)+1 *(11-10)=30$ score 
The scores of all challenges and legitimacy criteria were calculated in this way to determine their overall ranking. The results are presented in Tables 7 to 9 .

Table 6- The scores and rankings of the challenges of transnational entrepreneurs

\begin{tabular}{|c|c|c|}
\hline Challenge & Score & Rank \\
\hline Cultural differences & 30 & 7 \\
\hline Lack of strong ties & 16 & 9 \\
\hline Procuring funding & 45 & 2 \\
\hline Building a network & 42 & 3 \\
\hline The market \& competition & 31 & 6 \\
\hline Unfamiliarity with the Canadian business & & \\
\hline environment & 49 & 1 \\
\hline \multicolumn{3}{|l|}{ Lack of knowledge of Canadian banks and legal } \\
\hline restrictions & 17 & 8 \\
\hline Preparing an effective business \& marketing plan & 32 & 5 \\
\hline \multicolumn{3}{|l|}{ Insufficient understanding of Canadian business } \\
\hline language & 42 & 3 \\
\hline Difficulty communicating hi-tech ideas & 12 & 11 \\
\hline Discrimination & 14 & 10 \\
\hline
\end{tabular}

As illustrated in Table 6 and Figure 8, the most significant challenge for new transnational entrepreneurs is their lack of knowledge of the Canadian business environment, followed by the challenges of procuring funding, building a network, and gaining an understanding of the language of business. Based on these results, challenges associated with discrimination and trying to communicate hi-tech ideas are not as significant for NTVs. 


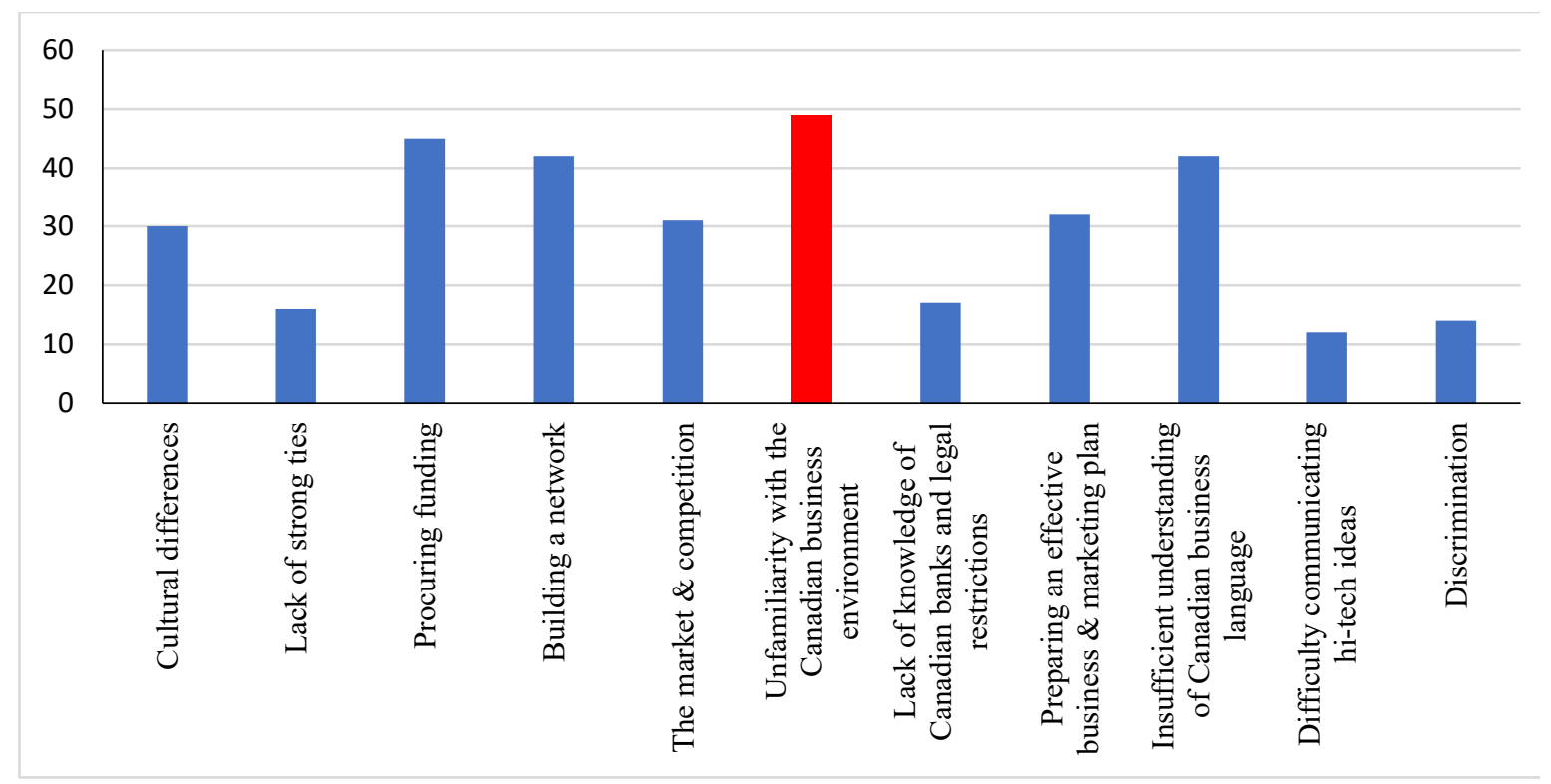

Figure 8- The scores of the challenges of transnational entrepreneurs

Table 7- The scores and ranking of legitimacy criteria from the perspective of banks

\begin{tabular}{lll}
\hline Criterion & Score & Rank \\
\hline Amount of owner investment & 36 & 2 \\
Amount of investment by other investors & 40 & 1 \\
Being in the production phase or having the business & 36 & 2 \\
running & 27 & 7 \\
Experience \& background of the founder and director & 30 & 6 \\
Strong business and marketing plan & 36 & 2 \\
Excellent credit history and high credit score & 22 & 8 \\
Tax documents and history of paying taxes & 20 & 9 \\
Number of employees & 32 & 5 \\
Loan security & 1 & 10 \\
Innovative idea & & 5
\end{tabular}

The most important legitimacy criterion in the view of banks, as shown in Table 7 and Figure 9, is the amount of investment by other investors. Other key criteria include the amount of owner investment, being in the production phase or already having the business 
running, and an excellent credit history. The results show that neither having an innovative idea or a certain number of employees are particularly important to banks.

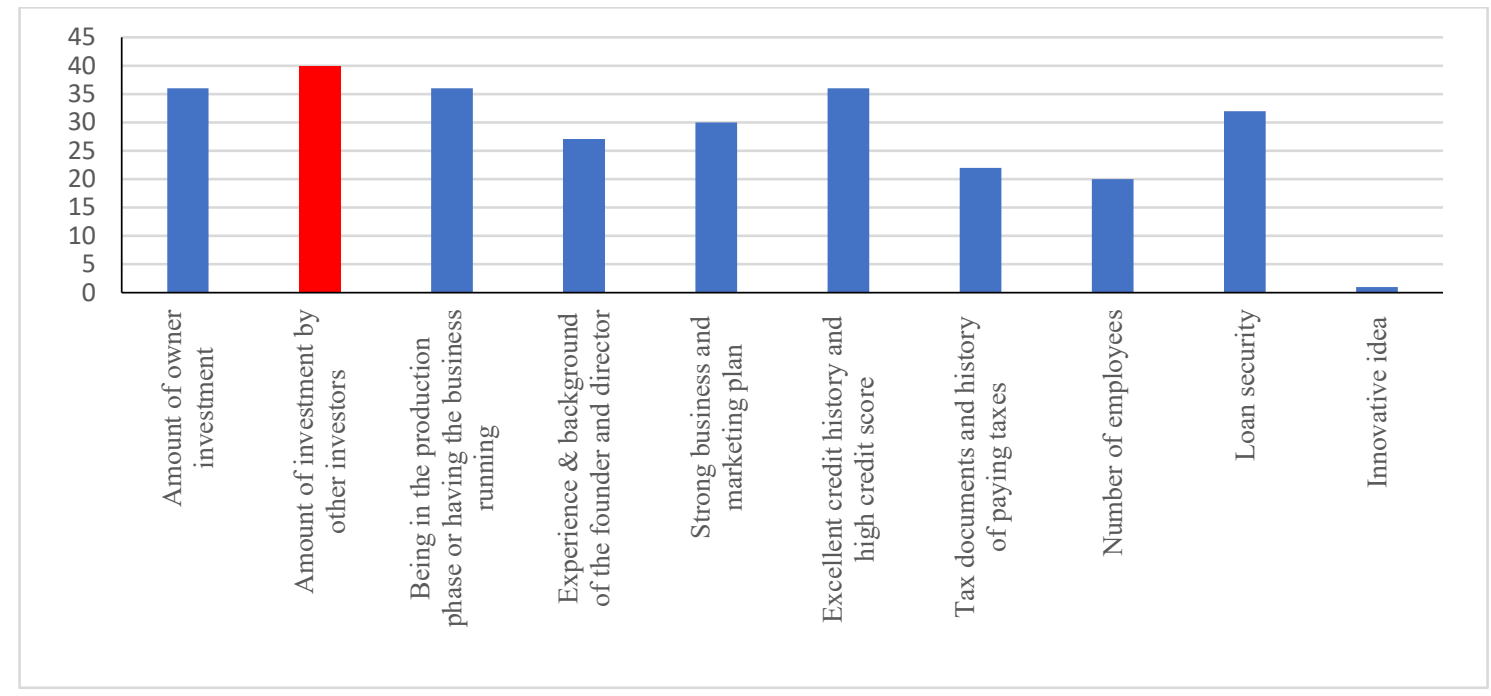

Figure 9- The scores of legitimacy criteria from the perspective of banks 
Table 8- The scores and rankings of the legitimacy criteria from the perspective of government agencies

\begin{tabular}{lcc}
\hline Criterion & Score & Rank \\
\hline Amount of owner investment & 29 & 7 \\
Amount of investment by other investors & 34 & 2 \\
Being in the production phase or having the business & 33 & 1 \\
running & 40 & \\
Experience \& background of the founder and & & 2 \\
director & 34 & 9 \\
Strong business and marketing plan & 7 & 8 \\
Excellent credit history and high credit score & 18 & 2 \\
Tax documents and history of paying taxes & 34 & 10 \\
Number of employees & 6 & 2 \\
Loan security & 34 & \\
Innovative idea & & \\
\hline
\end{tabular}

Based on the results displayed in Table 8 and shown in Figure 10, government agencies consider the experience and background of the company's founder and director to be the most important legitimacy criterion. The results also found the amount of investment by other investors, having a strong business and marketing plan, the number of employees, and the innovativeness of the business idea to be significant factors. Loan security and an excellent credit history, on the other hand, were not deemed significant criteria in the view of government agencies. 


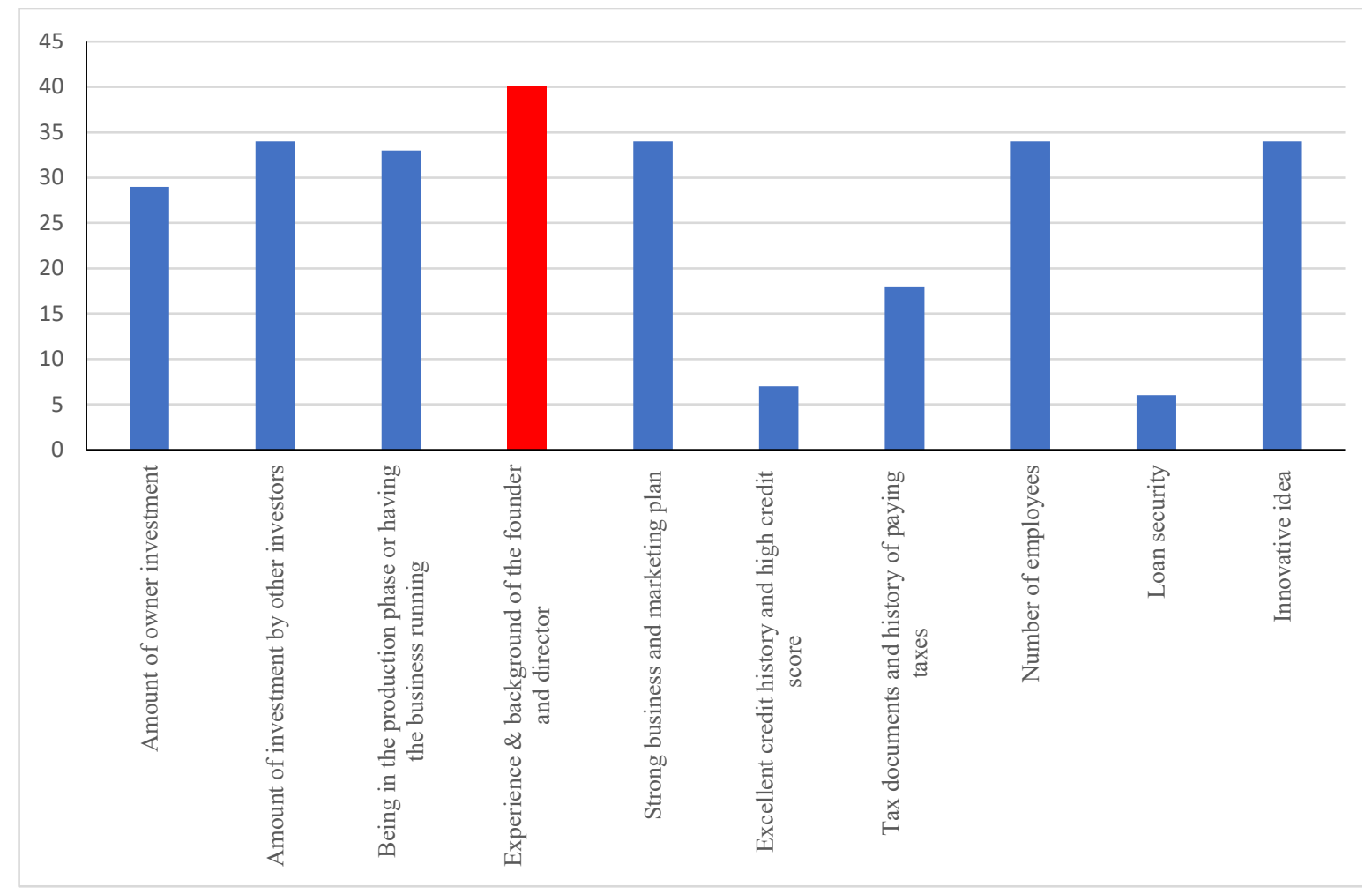

Figure 10- The scores of the legitimacy criteria from the perspective of government agencies

\subsection{Chapter summary}

In this chapter, the data collected from six case studies as well as two interviews with bank advisors were analyzed. The first subsection provided information about CanadianIranians in Canada. Data from two interviews with bank advisors, six case studies, and participant observation were then summarized and coded according to the grounded theory method. The findings resulted in 11 challenges and 10 legitimacy criteria from the perspective of grant providers and financiers. Applying the Borda count method, the challenges and criteria of legitimacy were ultimately prioritized based on participants' opinions (table 7, table 8 and table 9). 


\section{Discussion}

This chapter provides a discussion of the analysis of the results detailed in chapter 4 to build a theory grounded in the objectives of the research. The chapter is organized into three streams according to the research objectives: challenges, criteria of legitimacy, and legitimacy mechanisms.

\subsection{Challenges}

Based on the findings of the case studies, there are at least nine significant challenges for NTVs looking to demonstrate their legitimacy, as shown in Table 7. Of these nine challenges, four are very similar to challenges noted in the extant literature, especially by Chen \& Tan (2009), Gangadhar \& Manohar (2015), and Vertovec (2004) (Table 10).

Table 9- Comparison of challenges facing NTVs: Case studies vs. literature

Challenges based on case studies Challenges based on the literature

Cultural differences

Lack of strong ties

Procuring funding

Building a network

The market \& competition

Unfamiliarity with the Canadian business environment

Lack of knowledge about Canadian banks and legal restrictions

Preparing an effective business \& marketing plan

Insufficient understanding of Canadian business language

\section{Social and cultural incompatibility}

Fragility and the need for continuous maintenance and renewal

Access to local resources

Access to networks

Buyers or customers lack knowledge of transnational firms

Psychosocial concerns

National security 
The analysis of the data from the case studies showed that the most considerable challenge for NTVs is a lack of knowledge about the business environment in the host country. Many immigrant entrepreneurs, therefore, assess the market and business environment of the host country based on their experience in their country of origin. If the business rules, ethics, professionalism, or overall environment of the two countries are very different, this can cause major difficulties for new immigrants attempting to adapt to the host business environment. The second most important challenge is funding. While it is true that funding is a main challenge for all new ventures, it is often a more pronounced obstacle for NTVs because they have limited access to local resources, including funds. For example, entrepreneurs from the host country may have access to some funds from family and friends, but such sources of funding are often very limited for new immigrants, who typically have few relatives and friends in the host country. NTVs may also need to learn about the various sources of financing and funding available in the host country, which can pose further difficulties. The third major challenge according to the data analysis is building a network. Based on both the literature and the case studies, gaining access to a network is a significant challenge for NTVs. Challenges associated with insufficient knowledge of the language of business in the host country was ranked just after "building a network" by the case study participants. For immigrant entrepreneurs who may not be familiar with the host country's business language, this can make it difficult for them to carry out business functions such as negotiating, hiring, buying resources, and marketing.

Preparing an effective business and marketing plan was identified as the next most significant challenge for NTVs. As with procuring funding, creating an effective business and marketing plan is a challenge for every new business. However, due to cultural differences, it is often even more complicated for transnational entrepreneurs, who may be unfamiliar with the business plan and presentation styles of the host country. Although this challenge 
can, therefore, be linked to cultural differences as well as inadequate knowledge of the business environment, several case study participants emphasized the business and marketing plan as a separate challenge. Immigration agencies and incubators can be helpful sources of support for transnational entrepreneurs to overcome this challenge. For example, Ottawa World Skills has an entrepreneurship program for newcomers that helps them to learn about business plan development and business writing.

The next two challenges identified by case study participants were the market and competition and cultural differences. For Iranian-Canadian entrepreneurs, in particular, the market and competition may be a challenge because of the vast differences between Iran and Canada in this regard. The Canadian market is one of the largest economies in the world and is subsequently subject to a high rate of competition, especially in the technology sector. In contrast, the Iranian market is more isolated and less competitive. Even though Iran is a huge market, more than 35 years of US sanctions and about eight years of EU sanctions have had a significant impact on the economy. All sectors in Iran, and perhaps especially the technology sector, are cut off from international competition, and it is thus a very lucrative and easy market for technology entrepreneurs. Such differences could potentially explain why several case study participants faced challenges with the Canadian market and competition. Finally, cultural differences, despite being ranked seventh of the 11 challenges, are a very important factor insofar as they often exacerbate other challenges such as preparing an effective marketing and business plan, gaining knowledge of the business environments, and - to some extent - the market and competition. Each of the remaining three challenges were only noted by one case study participant as a significant challenge, and few of the other participants considered them challenges. For this reason, those factors received low scores and are not viewed as major challenges for NTVs. 


\subsection{Criteria of legitimacy}

Case study participants proposed ten important criteria of legitimacy in the eyes of financiers and grant providers: the amount of investment by external investors; the amount of owner investment; being in the production phase or already having the business running; the experience and background of the founder and director; the strength of the business and marketing plan; an excellent credit history and high credit score; tax documents and history of paying taxes; the number of employees; loan security; and an innovative business idea.

Based on the data analysis, the most important criterion of legitimacy in the eye of banks is the amount of investment in the business by external investors, while the experience and background of the founder and director is most important to grant providers.

According to the literature on the subject, and especially Fisher et al. (2017), Fisher et al. (2016), and Uberbacher (2014), there are five main criteria of legitimacy from the perspective of government grant providers and financiers. To the best of the researcher's knowledge, no research study to date has focused on NTV legitimacy criteria in the eyes of financiers. Through interviews with a bank advisor from $\mathrm{RBC}$ and another from Scotiabank, the researcher identified tax records, collateral, and a strong business and marketing plan as the most important criteria for banks evaluating a new venture (whether transnational or not). These findings both share some parallels and somewhat differ from the literature, as demonstrated in Table 11. 
Table 10- Comparison of criteria of legitimacy: Case studies vs. literature

\begin{tabular}{ll}
\hline Cases & Literature \\
\hline Experience \& background of the founder and & Experience and background of the venture's team \\
director & \\
Strong business and marketing plan & Strong business and marketing plan \\
Tax documents and history of paying taxes & $\begin{array}{l}\text { Documentation of taxes paid } \\
\text { Contributing to knowledge/providing technological } \\
\text { breakthroughs }\end{array}$ \\
Innovative idea & \\
Amount of owner investment & \\
Amount of investment by other investors & \\
Being in the production phase or having the & \\
business running & \\
Excellent credit history and high credit score & \\
Number of Employees & \\
Loan security
\end{tabular}

Ties with prominent research institutions/universities/ well-known research scientists

For banks, the amount of investment (by the owner as well as other investors), the owner's credit history, and being in the production phase were the main criteria of legitimacy identified by case study participants. Grant providers, on the other hand, were seen as prioritizing the experience and background of the founder and director, strength of the business and marketing plan, number of employees, innovativeness of the business idea, and amount of investment by other investors when evaluating an NTV's legitimacy.

\subsection{Legitimacy mechanisms}

According to the analysis of the data, there are at least five steps transnational entrepreneurs should take to build legitimacy in the eyes of grant providers and financiers, as outlined below: 
1. To gain an understanding of the host country's business environment and language of business, transnational entrepreneurs should get help from government immigration agencies or the community from one's country of origin. It can also be helpful to start one's business in a university ecosystem or an incubator for additional support. At this stage, entrepreneurs should seek out assistance to learn how to develop and pitch their idea in view of market needs.

2. The next step is to develop a strong business and marketing plan with the help of those sought out for the first step.

3. Next, it is important to build a skilled team, which can also be done with the help of an ecosystem as well as immigrant communities in the host country.

4. After starting the business in a reputable ecosystem, the entrepreneur should find an investor(s) to demonstrate the legitimacy of the business to potential government resource providers. It is often preferable to find venture capitalists from one's country of origin, as convincing investors from Canada or other countries can be much more difficult.

5. Finally, to demonstrate legitimacy to potential financiers, an entrepreneur must maintain a presence in the market for several years and build an excellent credit history. Financing can be a good means of securing working capital and expanding one's business.

According to the literature, the following mechanisms are recommended for NTVs looking to build legitimacy:

1. Identity mechanisms, including the use of "cultural tools" such as images, symbols, and language (Fisher et al., 2017).

2. Associative mechanisms, including communicating with actors in a particular sphere, such as corporate elites, constructive organizations, prominent investors, 
etc. (Fisher et al., 2017). This step is comparable to the first step identified through the analysis of the case study data.

3. Organizational mechanisms, including the professionalism of the team, the team's background and experience, certifications, the business and marketing plan (Fisher et al., 2017), and work based on the market standards (DiMaggio \& Powell,1983, and Mayer \& Psycho, 1977).

\subsection{Chapter summary}

This chapter has discussed the results from chapter 4 in view of the objectives of the research as well as the existing literature. When compared to the findings of the case studies, most of the legitimacy mechanisms identified in the literature have been confirmed by this research. However, the case studies provided more granularity, with specific steps for acquiring legitimacy in the eyes of financiers and grant providers. 


\section{Conclusion}

Chapter 6 marks the conclusion of the research, bringing together the data from chapters 2,4 , and 5 . The first section of this chapter presents the theories derived from the chapter 5 outcomes. From there, the chapter will conclude with a discussion of the limitations of the research project as well as suggestions for future research.

\subsection{Theory of the research}

As noted in chapter 4 , the main challenges facing NTVs are:

- Unfamiliarity with the Canadian business environment

- Procuring funding

- Building a network

- Insufficient understanding of Canadian business language

- Preparing an effective business \& marketing plan

- The market \& competition

- Cultural differences

- Lack of knowledge of Canadian banks and legal restrictions

- Lack of strong ties

Of these challenges, the first four were given a score of more than 40 and can, therefore, be considered the most important challenges. The research findings support the following theory on the challenges of NTVs.

The most significant challenges that NTVs face in obtaining legitimacy from the perspective of various audiences are an insufficient understanding of the Canadian business environment and language; procuring funding; and building a network. 
According to the case studies examined in this project, the following criteria of legitimacy, listed in order of significance, are considered most important in the eyes of banks:

- Amount of investment by other investors

- Excellent credit history and high credit score

- Amount of owner investment

- Being in the production phase or having the business running

- Loan security

- Strong business and marketing plan

- Experience \& background of the founder and director

- Tax documents and history of paying taxes

- Number of employees

Based on the above ranking of the criteria, the second theory of this research is as follows: In the eyes of financiers, the most important criteria of legitimacy for NTVs are the amount of investment in the business and the credit history of the owner(s).

In terms of what criteria of legitimacy grant providers deem most important, the scores assigned to the above-mentioned list by case study participants resulted in the following ranking:

- Experience \& background of the founder and director

- Amount of investment by other investors

- Strong business and marketing plan

- Number of employees

- Innovative idea

- Being in the production phase or having the business running

- Amount of owner investment 
As such, the final theory of this research is that:

Grant providers consider the experience and background of the founder and director as well as the amount of investment by other investors to be the most important criteria of legitimacy for NTVs.

\subsection{Limitations of the research}

The research had five main limitations. Firstly, the criteria of legitimacy extracted from the interviews were the perception of transnational entrepreneurs from the criteria that they were assessed by banks/grant providers. Therefore, their misunderstanding about some criteria of assessment may affect the result of the research. As there were limited academic resources on the financiers' side, it might be more critical. Using the bankers' experience, helped the researcher to cover this issue. Secondly, the researcher was only able to locate a limited number of Iranian-Canadian transnational startups in the technology field. Although there are many Iranian entrepreneurs in Canada, finding startups is not an easy task because their businesses are in the early stages and they typically do not do much advertising at that point. Ultimately, the researcher got help from PACSO and the Iranian community in Montreal to connect with Iranian-Canadian entrepreneurs in Ottawa and Montreal, but of the 30 entrepreneurs the researcher invited to participate, only six agreed to do so. The researcher sought to study only technology businesses, but given these limitations, one case outside of the technology field was included among the case studies.

The third limitation of this project was communicating with the case study participants. Due in part to cultural factors, many Iranian entrepreneurs are uncomfortable discussing their financial situations, particularly in the case of failed ventures. Therefore, it took a considerable amount of time and effort to build trust with each of the participants. The forth limitation was the relative lack of resources related to the legitimacy of transnational ventures. 
There was plenty of research on the legitimacy of ventures and transnational ventures separately; however, there was virtually no research on the intersection of legitimacy and transnational entrepreneurship. Relatedly, the final limitation was that there were few academic resources on legitimacy criteria from the perspective of financiers. In view of this limitation, the researcher interviewed two Canadian banking advisors to gain insight into the criteria they use to evaluate the legitimacy of new ventures.

\subsection{Suggestions for future research}

This research has focused on the legitimacy of NTVs, which is a new area of research. Accordingly, there are numerous avenues that future researchers interested in this subject could take. For example, one opportunity for future study would be to test the theories of this research by data from other countries. Another approach would be to conduct the same research on transnational entrepreneurs from different countries of origin and compare the results. As mentioned in the limitation of the research, the perception of transnational entrepreneurs may affect the validity of the perceived criteria of legitimacy comes from the cases. Therefore, future researchers may choose cases from financiers and grant providers instead of entrepreneurs and compare the results. Another interesting topic would be choosing transnational entrepreneurs in the field of technology from top five immigrant ethnic groups to Canada and compare the results. They may also wish to choose a method other than the Borda count method to rank the challenges and criteria since this method does not show the relative importance of the ranked entities. Alternative options include Multiple Criteria Decision Makings (MCDM) methods such as the Analytical Hierarchy Process (AHP), the Best-Worth Method (BWM), and the Technique of Preference by Similarity to Ideal Solution (TOPSIS). 


\subsection{Chapter summary}

This chapter has detailed the theory that grew out of the research as well as the limitations of the study and suggestions for future research. In the first section, three theories aligned with the research questions were derived from the results presented in chapters 4 and 5 . Based on the Borda count method, the challenges and criteria that scored more than 40 were deemed the most important. Three main limitations of the research were then proposed in the second section. Finally, several suggestions for future studies were presented in the final section of the chapter. 


\section{References}

Alcantara, L., Mitsuhashi, H., \& Hoshino, Y. 2006. Legitimacy in international joint ventures: It is still needed. Journal of International Management, 12: 389-407.

Aldrich, H.E., \& Fiol, C.M. 1994. Fools rush in: The institutional context of industry creation. Academy of Management Review, 19: 645-670.

Baltar, F., \& Icart, I. B. 2013. Entrepreneurial gain, cultural similarity and transnational entrepreneurship. Global Networks, 13(2): 200-220.

Barney, J. 1991. Firm resources and sustained competitive advantage. Journal of Management, 17: 99-120.

Baxter, P., \& Jack, S. 2008. Qualitative case study methodology: Study design and implementation for novice researchers. Qualitative Report, 13: 544-559.

Benson, D. F., Brau, J. C., Cicon, J., \& Ferris, S. P. 2015. Strategically camouflaged corporate governance in IPOs: Entrepreneurial masking and impression management. Journal of Business Venturing, 30: 839-864.

Bruderl, J., \& Schussler, R. 1990. Organizational mortality: The liabilities of newness and adolescence. Administrative Science Quarterly, 35(3): 530-547.

Brzozowski, J., Cucculelli, M., \& Surdej, A. 2017. The determinants of transnational entrepreneurship and transnational ties' dynamics among immigrant entrepreneurs in ICT sector in Italy. International Migration, 55(3): 105-125.

Burnham, P. 2004. Research methods in politics. New York: Palgrave Macmillan.

Canada Small and Medium-Sized Enterprises 2016. https://canadasmallbusiness.ca/canada-small-medium-sized-enterprises-stats-2016, September 12, 2017. 
Cao, S., Salameh, M., Seki, M., \& St-Amant, P. 2015. Trends in firm entry and new entrepreneurship in Canada. Ottawa: Bank of Canada.

Certo, S. T. 2003. Influencing initial public offering investors with prestige: Signaling with board structures. Academy of Management Review, 28: 432-446.

Charmaz, K. 2006. Constructing grounded theory. Thousand Oaks, CA: Sage.

Chelariu, C., Bello, D. C., \& Gilliland, D. I. Legitimacy building strategies in conditions of discretionary legal enforcement: A logic of social action approach. Industrial Marketing Management, 43: 850-861.

Chen, W., \& Tan, J. 2009. Understanding transnational entrepreneurship through a network lens: Theoretical and methodological considerations. Entrepreneurship Theory and Practice, 33(5): 1079-1091.

Clarke, J. 2011. Revitalizing entrepreneurship: How visual symbols are used in entrepreneurial performances. Journal of Management Studies, 48: 1365-1391.

Cohen, B., Amorós, J. E., \& Lundy, L. 2017. The generative potential of emerging technology to support startups and new ecosystems: Elsevier.

D’Andrade, R. 1984. Cultural meaning systems In: RA Shweder \& R. LeVine (Eds.), Culture theory. Essays on mind, self and emotion (pp. 88-119): Cambridge: Cambridge University Press.

Deephouse, D. L. 1996. Does isomorphism legitimate? Academy of Management Journal, 39: 1024-1039.

Decker, A. 2015. Transnational entrepreneurship and opportunity recognition. In 1st Global Diaspora Business Conference 2015: Mansfield College, Oxford University

Delmar, F., \& Shane, S. 2004. Legitimating first: Organizing activities and the survival of new ventures. Journal of Business Venturing, 19: 385-410. 
DiMaggio, P. J., Powell, W. W. 1983. The iron cage revisited: Institutional isomorphism and collective rationality in organizational fields. American Sociological Review, 48: $147-160$.

Dimitratos, P., Buck, T., Fletcher, M., \& Li, N. 2016. The motivation of international entrepreneurship: The case of Chinese transnational entrepreneurs. International Business Review, 25: 1103-1113.

Drori, I., Honig, B., \& Wright, M. 2009. Transnational entrepreneurship: An emergent field of study. Entrepreneurship Theory and Practice, 33(5): 1001-1022.

Fisher, G., Kotha, S., \& Lahiri, A. 2016. Changing with the times: An integrated view of identity, legitimacy and new venture lifecycles. Academy of Management Review, 41: 383-409.

Fisher, G., Kuratko, D. F., Bloodgood, J. M., \& Hornsby, J. S. 2017. Legitimate to whom? The challenge of audience diversity and new venture legitimacy. Journal of Business Venturing, 32(1): 52-71.

Freeman, J., Carroll, G. R., \& Hannan, M. T. 1983. The liability of newness: Age dependence in organizational death rates. American Sociological Review, 48(5): 692-710.

Gangadhar, N., \& Manahor, B. M. 2015. Understanding transnational entrepreneurship. International Journal of Advances in Management and Economics, 4(6): 52-67.

Garud, R., Schildt, H. A., \& Lant, T. K. 2014. Entrepreneurial storytelling, future expectations, and the paradox of legitimacy. Organization Science, 25: 1479-1492.

Glick Schiller, N., Basch, L., \& Blanc-Szanton, C. 1992. Towards a transnationalization of migration: Race, class, ethnicity, and nationalism reconsidered. The Annals of the New York Academy of Sciences, 645: 24. 
Häikiö, L. 2007. Expertise, representation and the common good: Grounds for legitimacy in the urban governance network. Urban Studies, 44(11): 2147-2162.

Hargadon, A. B., \& Douglas, Y. 2001. When innovations meet institutions: Edison and the design of the electric light. Administrative Science Quarterly, 46: 476-501.

Haveman, H. A., Habinek, J., \& Goodman, L. A. 2012. How entrepreneurship evolves: The founders of new magazines in America, 1741-1860. Administrative Science Quarterly, 57: 585-624.

Higgins, M. C., \& Gulati, R. 2003. Getting off to a good start: The effects of upper echelon affiliations on underwriter prestige. Organization Science, 14: 244-263.

Human, S. E., \& Provan, K. G. 2000. Legitimacy building in the evolution of small-firm multilateral networks: A comparative study of success and demise. Administrative Science Quarterly, 45(2): 327-365.

IMMigroup. 2017. Iranian Immigration to Canada: History and Numbers. https://www.immigroup.com/news/iranian-immigration-canada-history-andnumbers, September 12, 2017.

Jennings, J. E., Jennings, P. D., \& Greenwood, R. 2009. Novelty and new firm performance: The case of employment systems in knowledge-intensive service organizations. Journal of Business Venturing, 24: 338-359.

Johnson, C., Dowd, T. J, \& Ridgeway, C. L. 2006. Legitimacy as a social process. Annual Review of Sociology, 32: 53-78.

Karlsson, T., \& Honig, B. 2009. Judging a business by its cover: An institutional perspective on new ventures and the business plan. Journal of Business Venturing, 24: 27-45. 
Kloosterman, R. C. 2010. Matching opportunities with resources: A framework for analysing (migrant) entrepreneurship from a mixed embeddedness perspective. Entrepreneurship and Regional Development, 22(1): 25-45.

Kostova, T., \& Zaheer, S. 1999. Organizational legitimacy under conditions of complexity: The case of the multinational enterprise. Academy of Management Review, 24(1): 64-81.

Kuratko, D. F., Brown, T. J. 2010. Emerging life sciences ventures: The quest for legitimacy. Business Horizons, 53: 211-220.

Lawrence, T. B., \& Suddaby, R. 2006. Institutions and institutional work. In S. Clegg, W. Nord, \& T. B. Lawrence (Eds.), Handbook of organization studies: London, England: Sage.

Leung D., Césaire Meh, and Yaz Terajima. 2008. Are There Canada-U.S. Differences in SME Financing? Bank of Canada Working Paper 2008-4.

Light, I. H. 1972. Ethnic enterprise in America: Business and welfare among Chinese, Japanese, and Blacks: Univ of California Press.

Lijphart, A. 1971. Comparative politics and the comparative method. American Political Science Review, 65(3): 682-693.

Lin, X., Guan, J., \& Nicholson, M. J. 2010, August 24. The transnational entrepreneur. Financial Post.

Lin, X., \& Tao, S. 2012. Transnational entrepreneurs: Characteristics, drivers, and success factors. Journal of International Entrepreneurship, 10: 50-69.

Lincoln, Y. S., \& Guba, E. G. 1985. Naturalistic inquiry. Beverly Hills, CA: Sage.

Lounsbury, M., \& Glynn, M. A. 2001. Cultural entrepreneurship: Stories, legitimacy, and the acquisition of resources. Strategic Management Journal, 22(6-7): 545-564. 
Mannani M. Rahimieh N., and Sheibani K. 2002. Iranian Community in Canada, Encyclopedia Iranica, http://www.iranicaonline.org/articles/canada-v-iraniancommunity-in-canada, August 16, 2018

Martens, M. L., Jennings, J. E., \& Jennings, P. D. 2007. Do the stories they tell get them the money they need? The role of entrepreneurial narratives in resource acquisition. Academy of Management Journal, 50: 1107-1132.

Meyer, J. W., \& Rowan, B. 1977. Institutionalized organizations: Formal structure as myth and ceremony. American Journal of Sociology, 83: 340-363.

Meyer, J. W., \& Scott, R. W. 1983. Centralization and the legitimacy problems of local government. In J. W. Meyer \& R. W. Scott (Eds.), Organizational environments: Ritual and rationality: 199-215. Beverly Hills, CA: Sage.

Mill, J. S. 1973. A system of logic, ratiocinative and inductive: Being a connected view of the principles of evidence and the methods of scientific investigation, Toronto: University of Toronto Press.

Miller, S. R., \& Parkhe, A. 2002. Is there a liability of foreignness in global banking? An empirical test of banks' x-efficiency. Strategic Management Journal, 23: 55-75.

Mitchell, D. T. 2015. Internal and external factors affecting the perception of entrepreneurial opportunities. American Journal of Entrepreneurship, 1.

Muegge, S. 2004. Independent start-ups and corporate spin-outs in the Ottawa high-tech community. Unpublished master thesis, Carleton University, Ottawa, ON.

National Household Survey: Data tables. 2011. Www12.statcan.gc.ca. http://www12.statcan.gc.ca, June 20, 2017. 
Navis, C., \& Glynn, M. A. 2010. How new market categories emerge: Temporal dynamics of legitimacy, identity, and entrepreneurship in satellite radio, 1990-2005. Administrative Science Quarterly, 55: 439-471.

Navis, C., \& Glynn, M. A. 2011. Legitimate distinctiveness and the entrepreneurial identity: Influence on investor judgments of new venture plausibility. Academy of Management Review, 36: 479-499.

Norman, P. M., Artz, K. W., \& Martinez, R. J. 2007. Does it pay to be different? Competitive non-conformity under different regulatory regimes. Journal of Business Research, 60: $1135-1143$.

Oliver, C. 1991. Strategic responses to institutional processes. Academy of Management Review, 16: 145-179.

Patel, P. C., \& Conklin, B. 2009. The balancing act: the role of transnational habitus and social networks in balancing transnational entrepreneurial activities. Entrepreneurship Theory and Practice, 33(5): 1045-1078.

Pavlov, T., Predojević-Despić, J., Milutinović, S., Balli, B., \& Zhebo, E. 2014. Transnational networks, transnational entrepreneurship and the role of the state: The cases of Serbia and Albania. Belgrade, Serbia: Group 484 \& Institute of Social Sciences.

Portes, A., Haller, W., \& Guarnizo, L. 2001. Transnational entrepreneurs: The emergence and determinants of an alternative form of immigrant economic adaptation. Oxford: University of Oxford. Transnational Communities Programme.

Portes, A., Guarnizo, L. E., \& Haller, W. J. 2002. Transnational entrepreneurs: An alternative form of immigrant economic adaptation. American Sociological Review, 67: 278298. 
Rahnema, S. 2017. Iranian Canadians. The Canadian Encyclopedia. http://www.thecanadianencyclopedia.ca/en/article/iranians/, October 8, 2017.

Rao, H. 1994. The social construction of reputation: Certification contests, legitimation, and the survival of organizations in the American automobile-industry: 1895-1912. Strategic Management Journal, 15: 29-44.

Rindova, V. P., Petkova, A. P., \& Kotha, S. 2007. Standing out: How new firms in emerging markets build reputation. Strategic Organization, 5: 31-70.

Rutherford, M. W., Buller, P. F., \& Stebbins, J. M. 2009. Ethical considerations of the legitimacy lie. Entrepreneurship Theory and Practice, 33: 949-964.

Saari, D.G., 1985. The optimal ranking method is the Borda Count. Northwestern University Discussion Paper.

Savolainen, J. 1994. The rationality of drawing big conclusions based on small samples: In defense of Mill's methods. Social Forces, 72(4): 1217-1224.

Saxenian, A. 2007. The New Argonauts: Regional advantage in a global economy, Boston, MA: Harvard University Press.

Scott, W. R. 1995. Institutions and organizations. Thousand Oaks, CA: Sage.

Scott, W. R. 2007. Institutions and organizations: Ideas and interests (5th ed.). Thousand Oaks, CA: Sage.

Sequeira, J. M., Carr, J. C., \& Rasheed, A. A. 2009. Transnational entrepreneurship: Determinants of firm type and owner attributions of success. Entrepreneurship Theory and Practice, 33(5): 1023-1044.

Singh, J. V., Tucker, D. J., House, R. J. 1986. Organizational legitimacy and the liability of newness. Administrative Science Quarterly, 31: 171-193. 
Small

and

medium-sized

enterprises

financing.

2014

http://tccim.ir/images/Docs/EcoReport33.pdf, September 17, 2017, Tehran Chamber of Commerce, Industrial, Mines, and Agriculture.

Starr, J. A., \& MacMillan, I. C. 1990. Resource cooptation via social contracting: Resource acquisition strategies for new ventures. Strategic Management Journal, 11: 79-92.

Stinchcombe, A. L., \& March, J. 1965. Social structure and organizations. Handbook of organizations, 7: 142-193.

Stuart, T. E., Hoang, H., \& Hybels, C. 1999. Interorganizational endorsements and the performance of entrepreneurial ventures. Administrative Science Quarterly, 44: $315-349$.

Suchman, M. C. 1995. Managing legitimacy: Strategic and institutional approaches. Academy of Management Review, 20: 571-610.

Suddaby, R., \& Greenwood, R. 2005. Rhetorical strategies of legitimacy. Administrative Science Quarterly, 50: 35-67.

Swidler, A. 1986. Culture in action: Symbols and strategies. American Sociological Review, 51: $273-286$.

Tan, J., Shao, Y., \& Li, W. 2013. To be different, or to be the same? An exploratory study of isomorphism in the cluster. Journal of Business Venturing, 28: 83-97.

Terjesen, S., \& Elam, A. 2009. Transnational entrepreneurs' venture internationalization strategies: A practice theory approach. Entrepreneurship Theory and Practice, 33(5): 1093-1120.

The 20 World's Richest Persian Entrepreneurs. 2016. http://www.boxnewsbox.com/the-20worlds-richest-persian-entrepreneurs-2016/17/, May 18, 2017. 
Tost, L. P. 2011. An integrative model of legitimacy judgments. Academy of Management Review, 36(4): 686-710.

Überbacher, F. 2014. Legitimation of new ventures: A review and research program. Journal of Management Studies, 51(4): 667-698.

Ueberbacher, F. 2013. Exploring Legitimation Strategies of New Ventures (Doctoral dissertation), University of St. Gallen.

Urbano, D., Toledano, N., \& Ribeiro-Soriano, D. 2011. Socio-cultural factors and transnational entrepreneurship: A multiple case study in Spain. International Small Business Journal, 29(2): 119-134.

Van Werven, R., Bouwmeester, O., \& Cornelissen, J. P. 2015. The power of arguments: How entrepreneurs convince stakeholders of the legitimate distinctiveness of their ventures. Journal of Business Venturing, 30: 616-631.

Vertovec, S. 2004. Trends and impacts of migrant transnationalism (WP-04-03). Oxford, England: Centre on Migration, Policy and Society.

Wadhwa, V., Saxenian, A., Rissing, B. A., \& Gereffi, G. 2007. America's new Immigrant entrepreneurs: Part I.

Waldinger, R., \& Fitzgerald, D. 2004. Transnationalism in question. American Journal of Sociology, 109(5): 1175-1195.

Weber, K., \& Dacin, M. T. 2011. The cultural construction of organizational life: Introduction to the special issue. Organization Science, 22: 287-298.

Wiklund, J., Baker, T., \& Shepherd, D. 2010. The age-effect of financial indicators as buffers against the liability of newness. Journal of Business Venturing, 25: 423-437.

Wry, T., Lounsbury, M., \& Glynn, M. A. 2011. Legitimating nascent collective identities: Coordinating cultural entrepreneurship. Organization Science, 22: 449-463. 
Wong, L. L., \& Ng, M. 2002. The emergence of small transnational enterprise in Vancouver: The case of Chinese entrepreneur immigrants. International Journal of Urban and Regional Research, 26(3): 508-530.

Yeung, H. W.-C. 2002. Entrepreneurship in international business: An institutional perspective. Asia Pacific Journal of Management, 19(1): 29-61.

Yoon, S. J. 2017. Cultural Brokerage and Transnational Entrepreneurship: South Korean and Korean Chinese Entrepreneurs in Beijing's Koreatown. Korea Observer, 48, 2, 387 419.

Zaheer, S. 1995. Overcoming the liability of foreignness. Academy of Management Journal, 38(2): 341-363.

Zaheer, S., \& Mosakowski, E. 1997. The dynamics of the liability of foreignness: A global study of survival in financial services. Strategic Management Journal, 18(6): 439464.

Zhou, M. 2004. Revisiting ethnic entrepreneurship: Convergencies, controversies, conceptual advancements. International Migration Review, 38(3): 1040-1074.

Zimmerman, M. A., \& Zeitz, G. J. 2002. Beyond survival: Achieving new venture growth by building legitimacy. Academy of Management Review, 27(3): 414-431.

Zott, C., \& Huy, Q. N. 2007. How entrepreneurs use symbolic management to acquire resources. Administrative Science Quarterly, 52: 70-105. 


\section{Appendix 1: Questionnaire}

Thank you for participating in the interview for my research thesis on "Legitimacy of transnational ventures". The objective of the research is finding the most important challenges and legitimacy criteria of new transnational ventures (NTVs). According to the interviews with some entrepreneurs in Canada, we have reached to some important challenges they faced to as well as some criteria of legitimacy in the eyes of banks and government agencies who provide grants or other help to entrepreneurs such as IRAP, Futurpreneur and Invest Ottawa. By completing this questionnaire, you help me to find the most important and the least important challenges and criteria of legitimacy as well as prioritizing them.

I appreciate your great cooperation in this research.

Definitions:

- "Transnational Venture" is a business that has established by an immigrant entrepreneur in Canada.

- "Legitimacy" means the credibility of a venture that evaluate by its stakeholders such as banks, government agencies (grant providers), customers, employees and investors. This research focuses on legitimacy in the eyes of banks and government agencies when they evaluate a business to finance it or to provide it grant and other help.

1- In the table below, please prioritize the challenges based their importance. 1 is the most important challenge and 11 is the lease important one. 


\begin{tabular}{|c|c|c|c|c|c|c|c|c|c|c|}
\hline 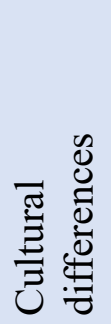 & 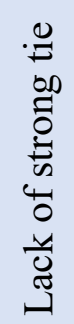 & 音 & 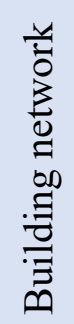 & 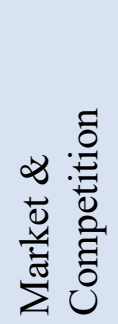 & 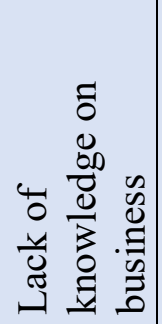 & 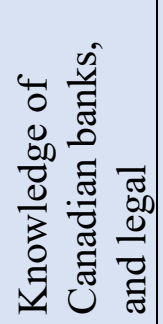 & 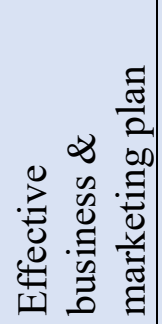 & 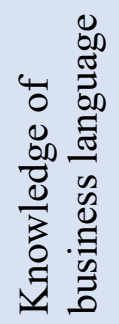 & 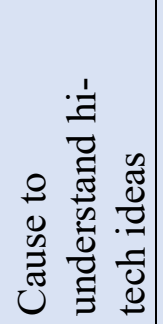 & 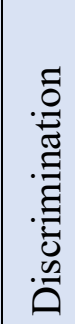 \\
\hline & & & & & & & & & & \\
\hline
\end{tabular}

2- In the table below, please prioritize the legitimacy criteria in the view of banks to finance a business based their importance. 1 is the most important criterion and 10 is the lease important one.

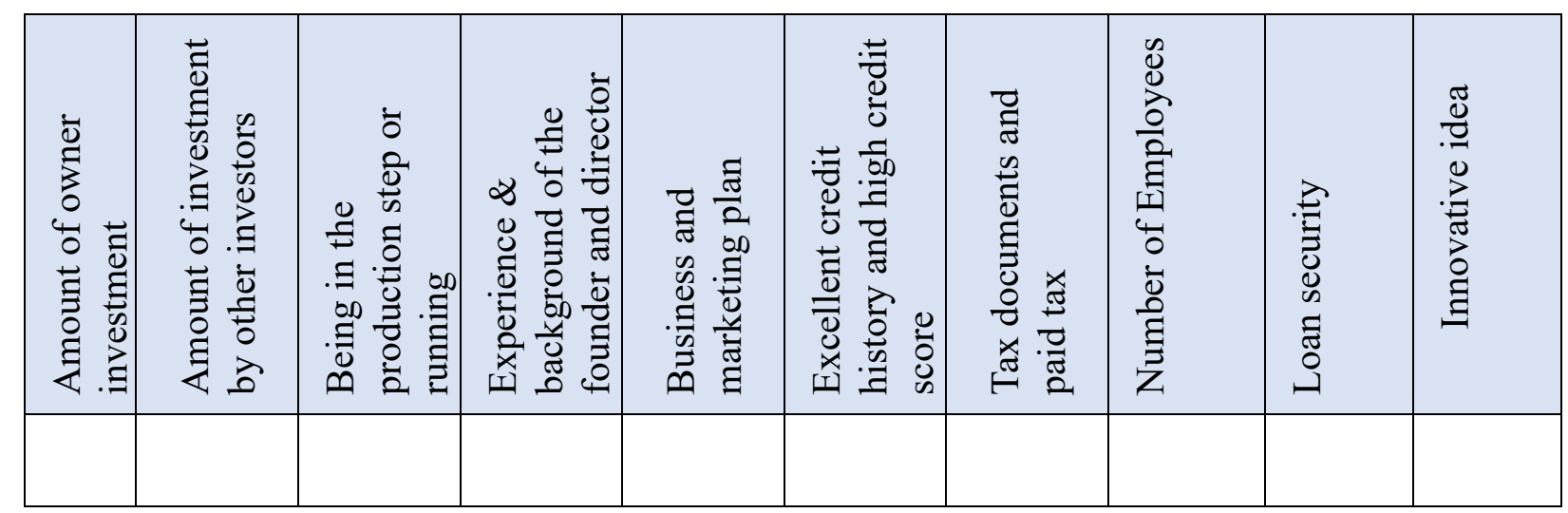

3- In the table below, please prioritize the legitimacy criteria in the view of government to finance a business based their importance. 1 is the most important criterion and 10 is the lease important one.

\begin{tabular}{|c|c|c|c|c|c|c|c|c|c|}
\hline 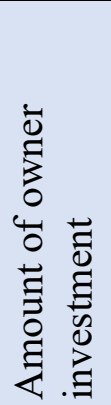 & 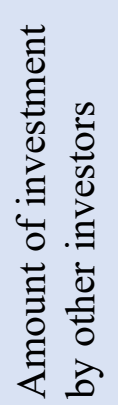 & 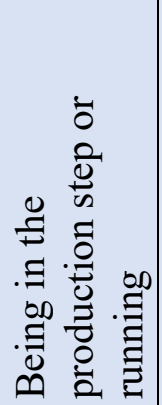 & 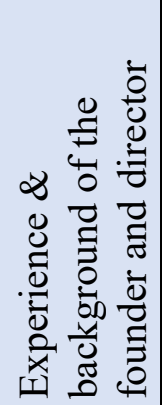 & 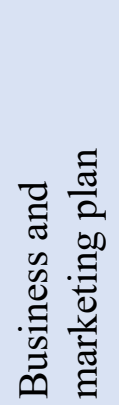 & 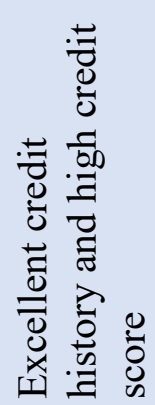 & 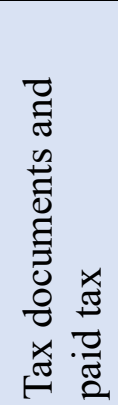 & 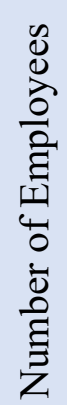 & 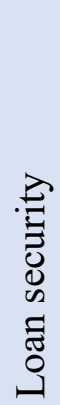 & $\begin{array}{l}\tilde{J} \\
.0 \\
0 \\
0 \\
.0 \\
0 \\
0 \\
0 \\
0\end{array}$ \\
\hline & & & & & & & & & \\
\hline
\end{tabular}

